\title{
A brewing understanding of the regulation of Bax function by Bcl-xL and Bcl-2
}

\author{
Thibaud T. Renault ${ }^{1,2}$, Laurent M. Dejean ${ }^{3}$, and Stéphen Manon ${ }^{4,5}$ \\ ${ }^{1}$ Helmholtz Center for Infection Research, Junior Research Group Infection Biology of Salmonella, \\ Inhoffenstraße 7, 38124 Braunschweig, Germany \\ ${ }^{2}$ Max Planck Institute for Infection Biology, Charitéplatz 1, 10117 Berlin, Germany \\ ${ }^{3}$ California State University of Fresno, Department of Chemistry, 2555 E. San Ramon Ave M/S \\ SB70, Fresno, CA 93740-8034, USA \\ ${ }^{4}$ CNRS, UMR5095, 1 Rue Camille Saint-Saëns, 33077 Bordeaux, France \\ ${ }^{5}$ Université de Bordeaux, 146 Rue Léo Saignat, 33076 Bordeaux, France
}

\section{Summary}

Bcl-2 family members form a network of protein-protein interactions that regulate apoptosis through permeabilization of the mitochondrial outer membrane. Deciphering this intricate network requires streamlined experimental models, including the heterologous expression in yeast. This approach had previously enabled researchers to identify domains and residues that underlie the conformational changes driving the translocation, the insertion and the oligomerization of the proapoptotic protein Bax at the level of the mitochondrial outer membrane. Recent studies that combine experiments in yeast and in mammalian cells have shown the unexpected effect of the antiapoptotic protein $\mathrm{Bcl}-\mathrm{xL}$ on the priming of Bax. As demonstrated with the BH3-mimetic molecule ABT-737, this property of Bcl-xL, and of Bcl-2, is crucial to elaborate about how apoptosis could be reactivated in tumoral cells.

\section{1-Introduction: Bcl-2 family members v/s BH3-containing proteins}

Apoptosis is the main type of programmed cell death in animals, participating to the modeling of organs during the development, and to tissue homeostasis during the whole life. It is activated following external or internal stimuli, and leads to a non-inflammatory response, opposite to other forms of cell death, such as necrosis.

It is generally considered that there are two types of apoptotic signaling pathways:

- the exogenous pathway, when death is initiated by the binding of an external ligand to a receptor, involves the direct activation of caspases, a group of proteases responsible for the implementation of apoptotic characteristics; 
- the endogenous pathway, when death is initiated "from the inside", for example through the activation of transcription factor $\mathrm{p} 53$ following an alteration to DNA, involves mitochondria. Alterations of the apoptotic program are associated with major age-related diseases, such as cancers when apoptosis is deficient, or degenerative diseases when apoptosis is over-activated. It is because of the existence of these major health issues that apoptosis is one of the most studied processes of cell biology in the last 20 years. A considerable amount of knowledge has been accumulated about the signaling pathways that regulate cell death, both under physiological and pathological situations. However, it still remains difficult to predict how these pathways modulate the molecular mechanisms underlying apoptosis, because of antagonistic effects between signaling pathways regulating cell death and survival, and the redundancy between parallel pathways. This intricacy is further increased in cell lines, where survival pathways are often over-activated while death pathways are repressed. This is why streamlined experimental models are needed to investigate the link between cellular and molecular regulations.

The group of proteins known as Bcl-2 family members are central players of apoptosis, because they form the interface between the early signaling events engaging the cells into the apoptotic process, and the later events conferring their apoptotic characteristics to the cells, leading to their elimination by the immune system (Adams and Cory, 2007, for a review). Bcl-2 family members are characterized by 4 homology domains, called $\mathrm{BH} 1$ to $\mathrm{BH} 4$. These domains are the keystones of these proteins' function and regulation, as they enable their mutual interaction within an intricate and highly regulated network.

Classically, the Bcl-2 family has been divided into 3 sub-families: anti-apoptotic proteins (e.g. Bcl2, Bcl-xL), pro-apoptotic proteins (Bax, Bak, Bok), and BH3-only proteins (e.g. Bid, Bad, Puma, Bim) (Fig.1). It is noteworthy that, while the two first sub-families are defined on the basis of a well-identified biological function, the last one is defined by default, on the basis of a structural property.

As a matter of fact, recent phylogenetic studies have shown that BH3-domains are present in many proteins other than the Bcl-2 family (Aouacheria et al., 2013) including, for example, the mammalian protein Beclin-1 (Liang et al., 1999), or the yeast protein Ybh3/Bxi1/YNL305C (Cebulski et al., 2011; Buttner et al., 2011). However, those BH3-domains do not derive from a common ancestor, opposite to the canonical BH3 domain of pro- and anti-apoptotic Bcl-2 family members, but rather result from a convergent evolution (Aouacheria et al., 2013). These studies redefined the BH3-domain as a short interacting motif, that is thus not limited to the Bcl-2 family members (Aouacheria et al., 2015). According to these studies, BH3-containing proteins could be re-organized into three categories (Aouacheria et al., 2013) (Fig.1):

- true Bcl-2 homologs, that contain three or four BH domains, and that can be anti-apoptotic (e.g. 
Bcl-2, Bcl-xL) or pro-apoptotic (Bax, Bak, Bok); Bid, which has only the BH3 domain, is considered as a true Bcl-2 homolog because of its overall structural similarity with Bcl-2;

- BH3-only proteins that contain a canonical BH3-domain (e.g. Bad, Puma, Bim);

- BH3-only proteins that contain a non-canonical BH3-domain (e.g. Beclin-1, Bnip3L/Nix, yeast Ybh3).

These studies show that true Bcl-2 homologs are only present in animals: vertebrates (including Bcl-2, Bax, and their homologs in non-mammalian vertebrates), nematode (C.elegans Ced-9) and insects (D.melanogaster Buffy and DeBcl). The same observation can be done for proteins containing a canonical BH3-domain, in vertebrates (including Bid, Puma, Bad) and in the nematode (Egl-1). All the BH3-containing proteins found in non-animal organisms contain a divergent domain, e.g. Ybh3 in the yeast S.cerevisiae, Rad9 in the yeast S.pombe, MCF in the bacterium P.luminescens, and viral proteins such as the protein CORE from the hepatitis $\mathrm{C}$ virus (Aouacheria et al., 2013). These proteins may have a function that is unrelated to the Bcl-2 family. For example, yeast Ybh3/Bxi1/YNL305C is involved in the UPR response and might modulate calcium dynamics (Cebulski et al., 2011), as shown for its bacterial homolog (Chang et al., 2014). However, like all the proteins containing a divergent $\mathrm{BH} 3$-domain, it might be potentially able to bind to Bcl-2 homologs, namely Bax, particularly when it is over-expressed. Conversely, Bcl-2 homologs might regulate the function of proteins containing a divergent $\mathrm{BH} 3$ domain, independently from apoptosis: as an example, it has been proposed that the pro-autophagic function of Beclin-1 is negatively regulated by the overexpression of Bcl-2 (Pattingre et al., 2005), although the effect of Bcl-2 on autophagy might also be indirect (Lindqvist et al., 2014).

\section{2-Bcl-2 family, MOMP and cytochrome c}

Bcl-2 homologs function is essential to the regulation of mitochondrial outer membrane permeabilization (MOMP), the key event irreversibly engaging the cells towards death. Following MOMP, a group of particular proteases, the caspases, are activated. This activation occurs through two processes: (1) procaspases are cleaved into two subunits and reorganized into active heterotetramers and (2) IAPs, a family of caspases inhibitors, are inactivated.

There is now a large consensus among investigators to consider that MOMP is caused by the formation of a large pore in the mitochondrial outer membrane (MOM), that enables the release of several proteins from the mitochondrial intermembrane space to the cytosol. Five of these proteins have been identified as 'apoptogenic factors' and are described below (Fig.2):

- Cytochrome c $(12.5 \mathrm{kDa})$ is a central soluble component of the electron transport chain; when released, it binds to Apaf-1, forming a complex that catalyzes the cleavage and the activation of caspase-9. 
- Smac/Diablo (25kDa) binds to IAPs, promoting their degradation, and thus preventing the inhibition of caspases.

- Omi/HtrA2 $(49 \mathrm{kDa})$ is a protease that inactivates IAPs.

- Endonuclease G (28kDa) participates to chromatin degradation.

- Apoptosis-Inducing Factor (AIF, 61kDa) is a redox protein that participates to the regulation of the respiratory chain. During apoptosis, it participates to chromatin condensation, but its precise function remains elusive.

It is still unclear whether these proteins, that have different sizes, are released simultaneously and through the same mechanism. Indeed, most studies are done on cultured cells with a sustained apoptotic trigger (such as the addition of an antitumoral drug). Under these conditions, apoptosis is followed by necrosis.

The initial steps of apoptosis might only involve a limited MOMP, without alteration of the inner mitochondrial membrane (see below). On the opposite, the secondary necrotic process might be associated to the activation of the large unselective channel called the mitochondrial Permeability Transition Pore (mPTP), that induces the permeabilization of the inner mitochondrial membrane (Bernardi et al., 2015, for review). This is followed by a massive mitochondrial swelling leading to the unselective rupture of the MOM, and the release of the whole intermembrane space content into the cytosol (Fig.2). Consequently, the mechanistic aspects of selective MOMP should be studied at the early stages of the apoptotic process, when mPTP is still close.

Electrophysiological studies on MOM from apoptotic cells showed the presence of a large conductance channel, that also appeared in the MOM from yeast cells expressing human Bax (Pavlov et al., 2001), or on isolated membranes incubated with Bax oligomers (Dejean et al., 2005). Interestingly, the size of this channel was sufficient to transport cytochrome c $(12.5 \mathrm{kDa})$, but not to transport a bigger protein, such as hemoglobin tetramer $(60 \mathrm{kDa})$ (Dejean et al., 2005). Electrical properties of this channel showed the existence of different conductance substates, suggesting a process of stepwise Bax oligomerization (Martinez-Caballero et al., 2010). Recent studies showed that Bax oligomers form large ring-like structures in the MOM that could be assimilated to the pore of the MOMP machinery (Große et al., 2016; Salvador-Gallego et al., 2016).

Among the apoptogenic factors, cytochrome $\mathrm{c}$ is one of the most ubiquitous and conserved proteins in the whole living world (Margoliash and Fitch, 1968), a feature most certainly related to its central function as a mobile electron carrier that shuttles between respiratory complexes. As such, it can serve as a universal marker for MOMP, including in model systems that do not carry out canonical apoptosis. Most specifically, the release of cytochrome c became a standard in studies regarding the function of animal Bcl-2 homologs after they are expressed in yeast (Fig.3). The expression of human Bax was shown to promote the release of cytochrome $\mathrm{c}$ in yeast (Manon et al., 1997) even 
before it was shown in human cells (Jurgensmeier et al., 1998). Like in mammalian cells, several death signals in yeast, such as acetic acid treatment, induce dramatic mitochondrial morphological alterations and a non-selective release of intermembrane space proteins, that have homologies with mammalian apoptogenic factors (Eisenberg et al., 2007; Cheng et al. 2008; Pereira et al., 2008, for reviews) (Fig.2). Interestingly, Bax effects in yeast do not depend on other proteins that are released following death stimuli (Kissova et al., 2006), such as acetic acid treatment, that may induce a necrotic type of death depending on massive mitochondrial permeabilization resembling $\mathrm{mPTP}$ (Pereira et al., 2010). This supports the view that, in mammalian cells, only cytochrome would be released through Bax-formed channels, while other apoptogenic factors would be released through other systems, such as mPTP (Kroemer et al., 2007, for review) or ceramides channels (Colombini, 2010, for review).

Due to the ease to obtain large amounts of yeast biomass, cytochrome c can be easily quantified by redox spectrophotometry, and compared to non-released cytochromes, such as cytochrome $b$, a membrane-inserted component of respiratory complex III (Fig.3). This allowed measuring the activities of different Bax mutants, with more precision than western-blots quantification (Arokium et al., 2004, 2007; Renault et al., 2015). Furthermore, redox spectrophotometry measures the mitochondrial cytochrome c content after it has been assembled with heme in the mitochondrial intermembrane space (Gonzalez and Neupert, 1990), thus limiting the quantification to cytochrome $\mathrm{c}$ that has transited through mitochondria. On the opposite, western-blots against cytochrome $\mathrm{c}$ also reveal the heme-free apoprotein, before it has been assembled within the mitochondria, meaning that a deficient addressing might be erroneously taken for an increased release.

The redox spectrophotometry measurement of cytochrome $\mathrm{c}$ in yeast mitochondria, following the heterologous expression of human Bax mutants has provided a considerable amount of data about the domains, residues, and possible partners involved in Bax ability to interact with MOM and to release cytochrome c. For example, the consequences of the replacements of Proline residues at positions 8, 13 and 168 by smaller and more flexible Glycine/Alanine residues have pointed out the role of the mobility of the N-terminal unstructured domain and of the C-terminal $\alpha$-helix in Bax activation (Arokium et al., 2004). Electric charge inversions at different positions (Arg9/Asp154) confirmed that favoring the movement of these domains (by disrupting salt bridges), was sufficient to promote the localization of Bax to the MOM (Arokium et al., 2007). Furthermore, this method has allowed evidencing the involvement of the mitochondrial receptor Tom 22 in the adequate translocation of Bax (Bellot et al., 2007; Renault et al., 2012), and the direct activation of Bax by BH3-only proteins tBid (Gonzalves et al., 2005) and Puma (Gallenne et al., 2009). This method has thus proved to be an adequate measurement of the ability of Bax to permeabilize the MOM.

In parallel, Bax expression in yeast induces a reduction of yeast growth and a loss of viability. 
However, these phenotypes involve additional effects beyond the release of cytochrome c, and are

consequently less precise reporters of Bax effects on mitochondria than the direct measurement of cytochrome $\mathrm{c}$ release (Kissova et al., 2006). Nevertheless, they proved their usefulness for the rapid screening of factors that potentially modulate the effects of Bax (Xu and Reed, 1998; Pan et al., 2001; Laloux et al., 2010; Ubaidillah et al., 2013).

\section{3-Bax retrotranslocation}

For long, it had been considered that Bax translocation from the cytosol to the mitochondria was a unidirectional process. This came from the observation that, in non-apoptotic cells, Bax localization is essentially diffuse in the cytosol while, after apoptosis is triggered, it is relocated to mitochondria (Wolter et al., 1997) to form membrane-inserted oligomers that are responsible for MOMP (Antonsson et al., 2000, 2001). Since this process involves major conformational changes (Suzuki et al., 2000; Peyerl et al., 2007), it was hardly conceivable that these oligomers could be disassembled, and that Bax could go back to its previously inactive state in the cytosol. However, significant observations suggested that the passage from soluble/monomeric Bax to membraneinserted/oligomeric Bax is not a one-step process. For example, it has been shown that, during anoikis, Bax could be relocalized to mitochondria, but that the process was reversible (Owens et al., 2009). This, and other experiments, demonstrated that 'mitochondrial Bax' was not obligatorily 'membrane-inserted' Bax (Renault et al., 2013).

Structural studies have allowed designing a complex Bax mutant that has a constitutive mitochondrial localization but that cannot support the conformational change associated to the oligomerization, thus remaining incompetent for cytochrome $\mathrm{c}$ release. Under oxidative conditions, this mutant displays two internal disulfide bonds that constraint helices $\alpha 1$ and $\alpha 2$, and $\alpha 1-\alpha 2$ loop and $\alpha 6$, therefore blocking the 'opening' of Bax structure associated to its activation (Edlich et al., 2011). When expressed in HCT-116 or HeLa cells, a GFP-tagged version of this mutant displayed a mitochondrial localization and did not trigger apoptosis, as expected. Following the photobleaching of GFP fluorescence in cell nuclei, both nuclear and cytosolic fluorescence disappeared while mitochondrial fluorescence remained. This reflected the rapid dynamics of exchange between the nucleus and the cytosol, and its absence for mitochondrial Bax. However, by following the reappearance of the fluorescence in the cytosol, the authors showed that a fraction of mitochondrial Bax could be retrotranslocated from the mitochondria to the cytosol. Most interestingly, this retrotranslocation process was greatly accelerated when the anti-apoptotic protein $\mathrm{Bcl}-\mathrm{xL}$ was overexpressed (Edlich et al., 2011). This led the authors to conclude that, in non-apoptotic cells, (1) Bax subcellular localization followed a dynamic equilibrium between mitochondria and cytosol and that (2) anti-apoptotic proteins could displace this equilibrium towards a more cytosolic localization. An 
additional interesting observation was that a mutant of Bcl-xL deleted of the C-terminal $\alpha$-helix

$(\mathrm{Bcl}-\mathrm{xL} \Delta \mathrm{C})$ was unable to promote Bax retrotranslocation, and further experiments demonstrated that the deletion of the 4 last residues of Bcl-xL were sufficient to prevent it (Todt et al., 2013). The question remained whether this process was only dependent on the intrinsic properties of interaction between the two proteins, or also involved external factors (such as, for example, the presence of other Bcl-2 family members). Since yeast does not contain endogenous Bcl-2 family members, it is a powerful tool to answer this question. Bax was expressed alone, or co-expressed with full-length $\mathrm{Bcl}-\mathrm{xL}$ or truncated $\mathrm{Bcl}-\mathrm{xL} \Delta \mathrm{C}$ in a yeast mutant inactivated for the major vacuolar protease Pep4p (the yeast ortholog of cathepsin D), and in the presence of the general inhibitor of serine-proteases PMSF. Under these conditions, following the addition of an inhibitor of protein synthesis (cycloheximide), the cellular Bax content remained stable for at least 4 hours. Mitochondria were then isolated to measure the evolution of Bax mitochondrial content following cycloheximide addition. Since the total content was stable, any decrease of the mitochondrial content would indicate retrotranslocation. When expressed alone, mitochondrial Bax levels remained constant. When co-expressed with Bcl-xL, mitochondrial Bax levels were decreased by $50 \%$ within 2 hours. When co-expressed with Bcl-xL $\Delta \mathrm{C}$, mitochondrial Bax levels remained constant. Similar experiments were done in mouse pro-lymphocytic cells FL5.12, with the same results, showing that the experiment in yeast actually led to observations relevant to mammalian physiology. These results were therefore consistent with the hypothesis that Bcl-xL (but not Bcl$\mathrm{xL} \Delta \mathrm{C}$ ) was able to promote the retrotranslocation of Bax, when the two proteins were co-expressed in yeast. This demonstrated that the retrotranslocation of Bax by Bcl-xL was only dependent on molecular properties of $\mathrm{Bax}$ and $\mathrm{Bcl}-\mathrm{xL}$, without interference from factors present in mammalian cells and absent from yeast, such as other Bcl-2 family members (Renault et al., 2015). Importantly, no retrotranslocation was observed when a constitutively active mutant of Bax, carrying a substitution P168A (Arokium et al., 2004; Cartron et al., 2005) was used. This supports the view that, once it is inserted and oligomerized (since it is able to promote the release of cytochrome c), Bax cannot be retrotranslocated.

\section{4-Steady-state Bax subcellular localization}

Intuitively, the existence of Bax retrotranslocation suggests that, in the presence of Bcl-xL, the steady-state Bax localization should be more cytosolic than when Bax is expressed alone. This can be correlated with the classical view of over-expressed Bcl-xL (or Bcl-2) sequestering Bax away from mitochondria, thus preventing apoptosis by restraining Bax ability to reach and permeabilize MOM.

Opposite to this prediction, we observed that the over-expression of Bcl-xL or of Bcl-2 increased 
the mitochondrial localization of endogenous Bax in FL5.12 cells (Teijido and Dejean, 2010;

Renault et al., 2015). Strikingly, Bax mitochondrial content reached the same level as measured in parental cells committed to apoptosis through IL-3 removal. Although less marked, a similar effect was observed in HCT-116 cells overexpressing Bcl-xL, showing that it was not a unique property of FL5.12 cells.

We then investigated if this apparently paradoxical effect of Bcl-xL on Bax mitochondrial localization was only dependent on the interaction between $\mathrm{Bax}$ and $\mathrm{Bcl}-\mathrm{xL}$ or if other factors were involved, by doing the experiments in yeast. We observed that Bax mitochondrial content was increased when Bcl-xL was co-expressed with Bax in yeast. This last result showed that Bcl-xLmediated Bax increase at the mitochondria was a general phenomenon, that depended only on Bax and Bcl-xL.

Most interestingly, we observed that the co-expression of $\mathrm{Bcl}-\mathrm{xL} \Delta \mathrm{C}$ induced an even higher increase of Bax mitochondrial localization in FL5.12 cells, in HCT-116 cells, and in yeast (Renault et al., 2015). As discussed above, truncated Bcl-xL $\Delta \mathrm{C}$ is not able to promote Bax retrotranslocation. This suggests that $\mathrm{Bcl}-\mathrm{xL}$ regulates Bax mitochondrial localization through two opposed processes: retrotranslocation, for which $\mathrm{Bcl}-\mathrm{xL} \Delta \mathrm{C}$ is impaired, and translocation, promoted both by full-length Bcl-xL and truncated Bcl-xL $\Delta \mathrm{C}$ (Fig.4).

\section{5-Bax priming is enhanced in cells overexpressing Bcl-xLAC or Bcl-xL}

The immediate consequence of the increase in the steady-state level of mitochondrial Bax is a potentially higher ability to initiate apoptosis. However, the presence of Bcl-xL, and the interaction between the two proteins, obviously prevent Bax activation. This can be verified by the fact that IL-3 removal induced a lower level of apoptosis in Bcl-xL-overexpressing FL5.12 cells, than in parental cells. Here again, the inhibition only depends on the interaction between Bax and Bcl-xL since, in yeast, the effect of a constitutive mitochondrial and active mutant of Bax on mitochondrial permeabilization is also prevented by the co-expression of Bcl-xL.

On the other hand, the overexpression of Bcl-xL $\Delta \mathrm{C}$ does not prevent the apoptosis of FL5.12 cells induced by the removal of IL-3, and does not prevent the permeabilization of yeast mitochondrial membrane by a constitutively active Bax mutant. In line with these observations, coimmunoprecipitation assays showed that the interaction between $\mathrm{Bax}$ and $\mathrm{Bcl}-\mathrm{xL} \Delta \mathrm{C}$ was not detectable under conditions where the one between Bax and full-length $\mathrm{Bcl}-\mathrm{xL}$ was. This demonstrates that the presence of the $\mathrm{C}$-terminal $\alpha$-helix of $\mathrm{Bcl}-\mathrm{xL}$ is required for a stable interaction and subsequent efficient inhibition of Bax.

Furthermore, we observed that the expression of Bcl-xL $\Delta \mathrm{C}$ stimulated Bax-driven MOMP in yeast. This rather unexpected effect was dependent on the interaction between the two proteins, since it 
was abrogated by introducing the canonical G138A mutation in the BH1-domain of Bcl-xL $\Delta \mathrm{C}$ (Renault et al., 2015), that is known to prevent the interaction between the two proteins (Ottilie et al., 1997).

These results showed that, although it might not be stable enough to be detectable by coimmunoprecipitation, a transient interaction between $\mathrm{Bax}$ and $\mathrm{Bcl}-\mathrm{xL} \Delta \mathrm{C}$ occurs and is sufficient to increase mitochondrial Bax content, but is not sufficient to prevent Bax-induced permeabilization. This was not observed with full-length Bcl-xL since its interaction with Bax, while inducing translocation of the pro-apoptotic protein, was stable enough (detectable by coimmunoprecipitation, as a matter of fact) to also keep it inactive.

Since Bcl-xL $\Delta \mathrm{C}$ is not a natural variant of the protein, we searched for experimental conditions which could reveal that full-length Bcl-xL is also able to prime Bax. Experiments on purified recombinant proteins had previously shown that the binding, then release, of Bax and Bcl-xL could initiate the active conformation of Bax that can be detected with the 6A7 monoclonal antibody (Hsu and Youle, 1997). The release could be induced by peptides corresponding to the BH3-domain of canonical BH3-only proteins, such as Puma, or by BH3-mimetic molecules such as ABT-737 (Gautier et al., 2011).

Therefore we used ABT-737 to disrupt Bax/Bcl-xL interaction both in the FL5.12 and the yeast models. The addition of ABT-737 to parental FL5.12 cells did not induce apoptosis, consistently with previous works (Certo et al., 2006). On the opposite, the addition of ABT-737 to FL5.12 cells overexpressing Bcl-xL induced a significant level of apoptosis (Renault et al., 2015).

We observed that ABT-737 had no effect on the biomass of yeast cells expressing Bax alone, or Bcl$\mathrm{xL}$ alone, but it significantly decreased the biomass of cells co-expressing Bax and Bcl-xL. Although this result might not rely only on Bax-induced MOMP, for the reasons discussed above (Kissova et al., 2006), it is nevertheless in accordance with the effect of ABT-737 observed in FL5.12 cells.

These experiments show that, both in FL5.12 cells and in yeast, the transient interaction between Bax and Bcl-xL followed by the release of the interaction, promotes the activation of Bax, like previously reported using pure recombinant proteins. Also, the study of yeast cells co-expressing $\mathrm{Bax}, \mathrm{Bcl}-\mathrm{xL}$ (or Bcl-2) and BH3-only proteins, have suggested that the lasts could only activate Bax indirectly, through the inhibition of Bcl-xL or Bcl-2 (Gerecova et al., 2013). A sequential expression of $\mathrm{Bax}$ and $\mathrm{Bcl}-\mathrm{xL} / \mathrm{Bcl}-2$, then $\mathrm{BH} 3$-only proteins, could provide a mean to study whether a given BH3-only protein is able or not to promote the release of Bax under an active conformation. Considering the hypothesis proposed above, this should happen with all the BH3-only proteins, with small efficiency differences due to their higher or lower specificity towards Bcl-2 or Bcl-xL. This has interesting consequences on the potential efficiency of BH3-mimetic molecules in anti- 
tumoral therapy. These molecules were designed to prevent the inhibition of apoptosis by anti-

apoptotic Bcl-2 family members (essentially Bcl-2, Bcl-xL, and Mcl-1), that are overexpressed in most cancer cells (see e.g. Tang et al., 1998; Pena et al., 1999, Castilla et al., 2006). The fact that, by breaking the interaction between Bax and Bcl-2/xL, not only they liberate Bax, but they further activate it, renders these molecules even more desirable as anti-tumor therapy, provided that Bax is still expressed and not mutated.

\section{6-A correlation between Bax phosphorylation and its interaction with Bcl-xL?}

From the discussion above, Bcl-xL is able to stimulate both Bax translocation to the MOM, and Bax retrotranslocation to the cytosol. This might appear like a futile cycle, but actually results in a high turnover of Bax localization and, as we have observed, a high mitochondrial content of 'primed' Bax, ready to trigger apoptosis. This might make the system more reactive than if Bax was only sequestered away from mitochondria, since Bax is already on target, ready to be activated after the release of its interaction with $\mathrm{Bcl}-2 / \mathrm{Bcl}-\mathrm{xL}$. However, the efficiency of such a 'dynamic cycling' model implies that the interaction between Bax and Bcl-xL has different properties depending if it happens in the cytosol or in the MOM. This may rely on biochemical differences between cytosolic and mitochondrial Bax.

Bax phosphorylation on different residues has been observed by several groups (Gardai et al., 2004; Linseman et al., 2004; Xin et al., 2007). Two main residues, S163 and S184, are substrates of kinases, although this does not exclude that other residues could be targeted as well. S163 is phosphorylated by GSK3 $\beta$. This implies that T167 should also be phosphorylated, since the consensus site for GSK3 $\beta$ is $\operatorname{SxxxT}_{\mathrm{P}}\left(\mathrm{S}_{\mathrm{P}}\right)$. S184 is the target of different kinases, including AKT and

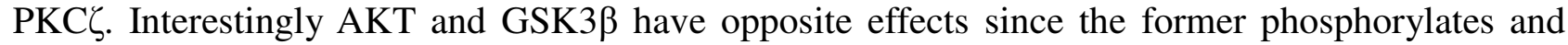
inactivates the later. Furthermore, AKT is generally involved in survival signaling pathways, while GSK3 $\beta$ is involved in death pathways (Martini et al., 2014), making their opposite effects on Bax rather predictable.

The heterologous expression of phosphomimetic and non-phosphorylatable mutants of S163 and S184 in yeast suggests that modifications of these residues participate to the regulation of the interaction of Bax with mitochondria (Arokium et al., 2007; Simonyan et al., 2016). When present alone, the mutation S163D does not have any particular phenotype, but it can activate Bax when it is combined to other mutations that facilitate intramolecular movements (Arokium et al., 2007).

The phosphorylation of S184 has attracted much interest because it is located in the C-terminal $\alpha$ helix, of which the movement is crucial to initiate Bax relocalization. It had been shown that the phosphorylation of S184 retained Bax away from mitochondria, while its dephosphorylation has the opposite effect (Gardai et al., 2004). This could be reproduced in yeast where the mutants S184A/V 
have a higher mitochondrial localization than the mutant S184D (Arokium et al., 2007; Simonyan et

al., 2016). However, this did not fully correlate with the ability of these mutants to induce MOMP. Indeed, the mutant S184D was surprisingly more efficient than mutants S184A/V (and wild-type Bax), to promote the release of cytochrome $\mathrm{c}$. These results suggest that the intrinsic capacity of the phosphomimetic mutant to induce MOMP was higher than that of the non-phosphorylatable mutant, that was apparently in contradiction with the fact that Bax phosphorylated on S184 is less able to induce apoptosis than the non-phosphorylated protein (Gardai et al., 2004). Part of the answer to this paradox might be related to the fact that, in mammalian cells, Bax is not expressed alone, but in the presence of, namely, anti-apoptotic proteins. Bax phosphomimetic and non-phosphorylatable mutants were then co-expressed with full-length Bcl-xL or truncated Bcl-xL $\Delta \mathrm{C}$ (Simonyan et al., 2016). We observed that the mitochondrial localization of the phosphomimetic mutant S184D did not differ from that of wild-type Bax, with an increase induced by Bcl-xL and a further increase induced by $\mathrm{Bcl}-\mathrm{xL} \Delta \mathrm{C}$, linked to the absence of retrotranslocation, as described above. Interestingly, the behavior of the non-phosphorylatable mutant S184A differed: its mitochondrial content was increased by Bcl-xL, like that of wild-type Bax and of the phosphomimetic mutant S184D, but it was not further increased, and was even about twice less increased, by Bcl-xL $\Delta \mathrm{C}$. Since the major difference between full-length $\mathrm{Bcl}-\mathrm{xL}$ and truncated $\mathrm{Bcl}-\mathrm{xL} \Delta \mathrm{C}$ is their capacity to retrotranslocate Bax, this result showed that retotranslocation did not have any effect on the mitochondrial localization of the non-phosphorylatable mutant Bax-S184A (Simonyan et al., 2016). This suggests that the ability of Bax to be retrotranslocated might depend on its phosphorylation, namely on S184. In mammalian cells, a correlation between the phosphorylation of S184 and the retrotranslocation of Bax by Bcl-xL had also been observed (Schellenberg et al., 2013): indeed, a mutant GFP-BaxS184V was retrotranslocated slower than GFP-BaxWT, paralleling the observations in yeast discussed above. Also, the overexpression of AKT stimulated GFP-BaxWT retrotranslocation. However, it was not mentioned whether the overexpression of AKT had or not an effect on the retrotranslocation of GFP-Bax-S184V, and it cannot be yet ascertained that this effect of AKT and the consequence of the phosphorylation of S184 on Bax retrotranslocation are strictly correlated. It should be noted that, when Bax and AKT were co-expressed in yeast, not all the effects of AKT were abolished by the substitution S184V, suggesting that part of the effect of AKT may occur through the phosphorylation of an additional residue besides S184 (Simonyan et al., 2016).

\section{7-Bcl-xL v/s Bcl-2}

Before Bcl-xL, the overexpression of $\mathrm{Bcl}-2$ had been shown to increase the mitochondrial localization of Bax in non-apoptotic FL5.12 cells (Teijido and Dejean, 2010). However, in spite of this apparent similarity, the consequences of Bcl-xL or Bcl-2 overexpression on Bax conformation 
were clearly distinct. Both proteins induced the conformational change of the N-terminus, leading

to a recognition by the $6 \mathrm{~A} 7$ antibody, and reveal the association of Bax to the MOM. But, while the overexpression of Bcl-2 also favored the formation of Bax oligomers (Teijido et al., 2010), the overexpression of Bcl-xL did not (Renault et al., 2013, 2015). It is yet difficult to draw any definitive conclusion about the consequences of this difference. Indeed, under both conditions, Bax remains inactive, being inhibited by its anti-apoptotic partner, and no MOMP was observed. But these observations emphasize the view that the overexpressions of Bcl-2 and Bcl-xL are not identical, considering their respective effects on Bax. This might be a crucial consideration for attempting to re-activate apoptosis in Bcl-2- or Bcl-xL-overexpressing tumoral cells.

Recent structural data brought major advances in the knowledge of Bax organization in the outer mitochondrial membrane. The interaction of $\operatorname{Bax} \Delta \mathrm{C}$ (deprived of its $\mathrm{C}$-terminal hydrophobic $\alpha$ helix) with the BH3 domain of Bid favors the formation of a symmetrical Bax dimer, in which helices $\alpha 5$ and $\alpha 6$ would first lay flat on the membrane instead of being inserted as a hairpin, and then would arrange a large pore by tilting in the membrane (Czabotar et al., 2014: Westphal et al., 2014). The formation of the pore as a juxtaposition of dimers has been proposed as an alternative to the membrane-inserted $\alpha$-helices (Bleicken et al., 2014; Subburaj et al., 2015). This model is compatible with recent microscopy images showing the ring-like organization of $\mathrm{Bax}$ in mitochondria of apoptotic cells (Salvador-Gallego et al., 2016; Große et al., 2016). It is also compatible with electrophysiological data suggesting that the pore formed by Bax have different incremental sizes (Martinez-Caballero et al., 2009).

In non-apoptotic FL5.12 cells overexpressing Bcl-2, the presence of oligomers similar in size to those observed in apoptotic cells have been observed (Renault et al., 2013), while no oligomer was detected in the same cells overexpressing Bcl-xL (Renault et al., 2015). By correlating these observations to the structural model of Bax oligomers, one could speculate that Bcl-2 would favor the formation of Bax oligomers that remain lain on the membrane, while $\mathrm{Bcl}-\mathrm{xL}$ prevents the formation of oligomers, maybe by stabilizing Bax dimers. In any case, the rupture of the interaction between Bax and its anti-apoptotic partner would be sufficient to promote the organization of the pore-forming oligomer.

\section{8-Concluding remarks}

The intrinsic pathway of apoptosis, that involves mitochondria, is triggered by signals originating within the cell, such as, typically, p53 expression. Nevertheless, most Bcl-2 family members are expressed at a basal level, both in tissues and in cultured cells. The presence of Bcl-2 family members, both in proliferating and post-mitotic cells, might not only reflect the requirement for a rapid response to apoptotic stimuli, but also non-apoptotic functions of these proteins. Namely, it 
has been shown that both Bcl-2 and Bcl-xL could regulate autophagy (Pattingre et al., 2005; Maiuri et al., 2007; Priault et al., 2010; Beaumatin et al., 2016). Interestingly, the effects of both proteins on autophagy are distinct, paralleling their distinct effect on Bax-regulation discussed above. It has also been shown that Bax could regulate mitochondrial dynamics (Karbowski et al., 2006; Cleland et al., 2011). In this short survey, we have shown that, even in non-apoptotic cells, the interactions between pro- and anti-apoptotic Bcl-2 family members determine the way a cell is able to respond to a potential apoptotic trigger, such as an anti-tumoral treatment. The fact that these properties are conserved in yeast demonstrates that they are dependent on their intrinsic molecular features. As a matter of fact, the heterologous expression in yeast continues to be an outstanding tool to study the molecular mechanisms underlying the function of these proteins.

\section{Aknowledgements}

The work in the lab of the authors has been supported by the CNRS, the ANR, the University of Bordeaux (to S.M.) and the California State University of Fresno (to L.M.D.).

\section{References}

Adams, J.M., Cory, S., 2007. The Bcl-2 apoptotic switch in cancer development and therapy. Oncogene 26, 1324-1337.

Antonsson, B., Montessuit, S., Lauper, S., Eskes, R., Martinou, J.C., 2000. Bax oligomerization is required for channel-forming activity in liposomes and to trigger cytochrome c release from mitochondria. Biochem. J. 345, 271-278.

Antonsson, B., Montessuit, S., Sanchez, B., Martinou, J.C., 2001. Bax is present as a high molecular weight oligomer/complex in the mitochondrial membrane of apoptotic cells. J. Biol. Chem. 276, 11615-11623

Aouacheria, A., Rech de Laval, V., Combet, C., Hardwick, J.M., 2013. Evolution of Bcl-2 homology motifs: homology versus homoplasy. Trends Cell Biol. 23, 103-111.

Aouacheria, A., Combet, C., Tompa, P., Hardwick, J.M., 2015. Redefining the BH3 Death Domain as a 'Short Linear Motif'. Trends Biochem Sci. 40, 736-748.

Arokium, H., Camougrand, N., Vallette, F.M., Manon, S., 2004. Studies of the interaction of substituted mutants of BAX with yeast mitochondria reveal that the $\mathrm{C}$-terminal hydrophobic alpha- 
helix is a second ART sequence and plays a role in the interaction with anti-apoptotic BCL-xL. J. Biol. Chem. 279, 52566-52573.

Arokium, H., Ouerfelli, H., Velours, G., Camougrand, N., Vallette, F.M., Manon, S. 2007., Substitutions of potentially phosphorylatable serine residues of Bax reveal how they may regulate its interaction with mitochondria. J. Biol. Chem. 282, 35104-35112.

Baines, C.P., Kaiser, R.A., Purcell, N.H., Blair, N.S., Osinska, H., Hambleton, M.A., Brunskill, E.W., Sayen, M.R., Gottlieb, R.A., Dorn, G.W., Robbins, J., Molkentin, J.D., 2005. Loss of cyclophilin D reveals a critical role for mitochondrial permeability transition in cell death. Nature 434, 658-662.

Bellot, G., Cartron, P.F., Er, E., Oliver, L., Juin, P., Armstrong, L.C., Bornstein, P., Mihara, K., Manon, S., Vallette, F.M., 2007. TOM22, a core component of the mitochondria outer membrane protein translocation pore, is a mitochondrial receptor for the proapoptotic protein Bax. Cell Death Differ. 14, 785-794

Beaumatin, F., El Dhaybi, M., Lasserre, J.P., Salin, B., Moyer, M.P., Verdier, M., Manon, S., Priault, M., 2016. N52 monodeamidated Bcl-xL shows impaired oncogenic properties in vivo and in vitro. Oncotarget 7, 17129-17143

Bernardi, P., Rasola, A., Forte, M., Lippe, G., 2015. The Mitochondrial Permeability Transition Pore: Channel Formation by F-ATP Synthase, Integration in Signal Transduction, and Role in Pathophysiology. Physiol Rev. 95, 1111-1155.

Bleicken, S., Jeschke, G., Stegmueller, C., Salvador-Gallego, R., García-Sáez, A.J., Bordignon, E., 2014. Structural model of active Bax at the membrane. Mol. Cell. 56, 496-505.

Büttner, S., Ruli, D., Vögtle, F.N., Galluzzi, L., Moitzi, B., Eisenberg, T., Kepp, O., Habernig, L., Carmona-Gutierrez, D., Rockenfeller, P., Laun, P., Breitenbach, M., Khoury, C., Fröhlich, K.U., Rechberger, G., Meisinger, C., Kroemer, G., Madeo, F., 2011. A yeast BH3-only protein mediates the mitochondrial pathway of apoptosis. EMBO J. 30, 2779-2792.

Cartron, P.F., Arokium, H., Oliver, L., Meflah, K., Manon, S., Vallette, F.M., 2005. Distinct domains control the addressing and the insertion of Bax into mitochondria. J. Biol. Chem. 280, 10587-10598 
Castilla, C., Congregado, B., Chinchón, D., Torrubia, F.J., Japón, M.A., Sáez, C., 2006. Bcl-xL is overexpressed in hormone-resistant prostate cancer and promotes survival of LNCaP cells via interaction with proapoptotic Bak. Endocrinology 147, 4960-4967

Cebulski, J., Malouin, J., Pinches, N., Cascio, V., Austriaco, N., 2011. Yeast Bax inhibitor, Bxi1p, is an ER-localized protein that links the unfolded protein response and programmed cell death in Saccharomyces cerevisiae. PLoS One 6, e20882.

Certo, M., Del Gaizo Moore, V., Nishino, M., Wei, G., Korsmeyer, S., Armstrong, S.A., Letai, A., 2006. Mitochondria primed by death signals determine cellular addiction to antiapoptotic BCL-2 family members. Cancer Cell 9, 351-365.

Chang, Y., Bruni, R., Kloss, B., Assur, Z., Kloppmann, E., Rost, B., Hendrickson, W.A., Liu, Q., 2014. Structural basis for a pH-sensitive calcium leak across membranes. Science 344, 1131-1135.

Cheng, W.C., Leach, K.M., Hardwick, J.M., 2008. Mitochondrial death pathways in yeast and mammalian cells. Biochim Biophys Acta 1783, 1272-1279

Chou, J.J., Li, H., Salvesen, G.S., Yuan, J., Wagner, G., 1999. Solution structure of BID, an intracellular amplifier of apoptotic signaling. Cell 96, 615-624.

Cleland, M.M., Norris, K.L., Karbowski, M., Wang, C., Suen, D.F., Jiao, S., George, N.M., Luo, X., Li, Z., Youle, R.J., 2011. Bcl-2 family interaction with the mitochondrial morphogenesis machinery. Cell Death Differ. 18, 235-247.

Colombini, M., 2010. Ceramide channels and their role in mitochondria-mediated apoptosis. Biochim Biophys Acta 1797, 1239-1244

Czabotar, P.E., Lessene, G., Strasser, A., Adams, J.M., 2014. Control of apoptosis by the BCL-2 protein family: implications for physiology and therapy. Nat. Rev. Mol. Cell Biol. 15, 49-63.

Eisenberg, T., Büttner, S., Kroemer, G., Madeo, F., 2007. The mitochondrial pathway in yeast apoptosis. Apoptosis 12, 1011-1023. 
Edlich, F., Banerjee, S., Suzuki, M., Cleland, M.M., Arnoult, D., Wang, C., Neutzner, A., Tjandra,

N., Youle, R.J., 2011. Bcl-x(L) retrotranslocates Bax from the mitochondria into the cytosol. Cell $145,104-116$.

Gallenne, T., Gautier, F., Oliver, L., Hervouet, E., Noël, B., Hickman, J.A., Geneste, O., Cartron, P.F., Vallette, F.M., Manon, S., Juin, P., 2009. Bax activation by the BH3-only protein Puma promotes cell dependence on antiapoptotic Bcl-2 family members. J. Cell Biol. 185, 279-290.

Gardai, S.J., Hildeman, D.A., Frankel, S.K., Whitlock, B.B., Frasch, S.C., Borregaard, N., Marrack, P., Bratton, D.L., Henson, P.M., 2004. Phosphorylation of Bax Ser184 by Akt regulates its activity and apoptosis in neutrophils. J. Biol. Chem. 279, 21085-21095.

Gautier, F., Guillemin, Y., Cartron, P.F., Gallenne, T., Cauquil, N., Le Diguarher, T., Casara, P., Vallette, F.M., Manon, S., Hickman, J.A., Geneste, O., Juin, P., 2011. Bax activation by engagement with, then release from, the BH3 binding site of Bcl-xL. Mol. Cell. Biol. 31, 832-844.

Gérecová, G., Kopanicová, J., Jaká, P., Běhalová, L., Juhásová, B., Bhatia-Kiššová, I., Forte, M., Polčic, P., Mentel, M., 2013. BH3-only proteins Noxa, Bik, Bmf, and Bid activate Bax and Bak indirectly when studied in yeast model. FEMS Yeast Res. 13, 747-754.

Gonzalez, D.H., Neupert, W., 1990. Biogenesis of mitochondrial c-type cytochromes. J. Bioenerg. Biomembr. 22, 753-768

Gonzalvez, F., Bessoule, J.J., Rocchiccioli, F., Manon, S., Petit, P.X., 2005. Role of cardiolipin on tBid and tBid/Bax synergistic effects on yeast mitochondria. Cell Death Differ. 12, 659-667.

Große, L., Wurm, C.A., Brüser, C., Neumann, D., Jans, D.C., Jakobs, S., 2016. Bax assembles into large ring-like structures remodeling the mitochondrial outer membrane in apoptosis. EMBO J. 35, 402-413

Hsu, Y.T., Youle, R.J., 1997. Nonionic detergents induce dimerization among members of the Bcl-2 family. J. Biol. Chem. 272, 13829-13834.

Jürgensmeier, J.M., Xie, Z., Deveraux, Q., Ellerby, L., Bredesen, D., Reed, J.C., 1998. Bax directly induces release of cytochrome c from isolated mitochondria. Proc. Natl Acad. Sci U S A. 95, 4997- 
5002.

Karbowski, M., Norris, K.L., Cleland, M.M., Jeong, S.Y., Youle, R.J., 2006. Role of Bax and Bak in mitochondrial morphogenesis. Nature 443, 658-662.

Kissová, I., Plamondon, L.T., Brisson, L., Priault, M., Renouf, V., Schaeffer, J., Camougrand, N., Manon, S., 2006. Evaluation of the roles of apoptosis, autophagy, and mitophagy in the loss of plating efficiency induced by Bax expression in yeast. J. Biol. Chem. 281, 36187-36197.

Kroemer, G., Galluzzi, L., Brenner, C., 2007. Mitochondrial membrane permeabilization in cell death. Physiol Rev. 87, 99-163.

Laloux, G., Deghelt, M., de Barsy, M., Letesson, J.J., De Bolle, X. 2010. Identification of the essential Brucella melitensis porin Omp2b as a suppressor of Bax-induced cell death in yeast in a genome-wide screening. PLoS One 5, e13274.

Liang, X.H., Jackson, S., Seaman, M., Brown, K., Kempkes, B., Hibshoosh, H., Levine, B., 1999. Induction of autophagy and inhibition of tumorigenesis by beclin 1. Nature 402, 672-676.

Lindqvist, L.M., Heinlein, M., Huang, D.C., Vaux, D.L., 2014. Prosurvival Bcl-2 family members affect autophagy only indirectly, by inhibiting Bax and Bak. Proc. Natl Acad. Sci. USA. 111, 85128517.

Linseman, D.A., Butts, B.D., Precht, T.A., Phelps, R.A., Le, S.S., Laessig, T.A., Bouchard, R.J., Florez-McClure, M.L., Heidenreich, K.A., 2004. Glycogen synthase kinase-3beta phosphorylates Bax and promotes its mitochondrial localization during neuronal apoptosis. J. Neurosci. 24, 999310002.

Maiuri, M.C., Le Toumelin, G., Criollo, A., Rain, J.C., Gautier, F., Juin, P., Tasdemir, E., Pierron, G., Troulinaki, K., Tavernarakis, N., Hickman, J.A., Geneste, O., Kroemer, G., 2007. Functional and physical interaction between Bcl-X(L) and a BH3-like domain in Beclin-1. EMBO J. 26, 25272539.

Manon, S., Chaudhuri, B., Guérin, M., 1997. Release of cytochrome c and decrease of cytochrome c oxidase in Bax-expressing yeast cells, and prevention of these effects by coexpression of Bcl-xL. 
FEBS Lett. 415, 29-32.

Margoliash, E., Fitch, W.M., 1968. Evolutionary variability of cytochrome c primary structures. Ann. N.Y. Acad. Sci. 151, 359-381

Martinez-Caballero, S., Dejean, L.M., Kinnally, M.S., Oh, K.J., Mannella, C.A., Kinnally, K.W., Assembly of the mitochondrial apoptosis-induced channel, MAC. J. Biol. Chem. 284, 1223512245.

Martini, M., De Santis, M.C., Braccini, L., Gulluni, F., Hirsch, E., 2014. PI3K/AKT signaling pathway and cancer: an updated review. Ann. Med. 46, 372-383

Ottilie, S., Diaz, J.L.,Chang, J., Wilson G., Tuffo, K.M., Weeks, S., McConnell, M., Wang, Y., Oltersdorf, T., Fritz, L.C., 1997. Structural and functional complementation of an inactive Bcl-2 mutant by Bax truncation. J. Biol. Chem. 272, 16955-16961

Owens, T.W., Valentijn, A.J., Upton, J.P., Keeble, J., Zhang, L., Lindsay, J., Zouq, N.K., Gilmore, A.P., 2009. Apoptosis commitment and activation of mitochondrial Bax during anoikis is regulated by p38MAPK. Cell Death Differ. 16, 1551-1562.

Pan, L., Kawai, M., Yu, L.H., Kim, K.M., Hirata, A., Umeda, M., Uchimiya, H., 2001. The Arabidopsis thaliana ethylene-responsive element binding protein (AtEBP) can function as a dominant suppressor of Bax-induced cell death of yeast. FEBS Lett. 508, 375-378.

Pattingre, S., Tassa, A., Qu, X., Garuti, R., Liang, X.H., Mizushima, N., Packer, M., Schneider, M.D., Levine, B., 2005. Bcl-2 antiapoptotic proteins inhibit Beclin 1-dependent autophagy. Cell $122 ; 927-939$.

Pena, J.C., Thompson, C.B., Recant, W., Vokes, E.E., Rudin, C.M., 1999. Bcl-xL and Bcl-2 expression in squamous cell carcinoma of the head and neck. Cancer 85, 164-170.

Pereira, C., Silva, R.D., Saraiva, L., Johansson, B., Sousa, M.J., Côrte-Real, M., 2008. Mitochondria-dependent apoptosis in yeast. Biochim Biophys Acta 1783, 1286-1302.

Pereira, C., Chaves, S., Alves, S., Salin, B., Camougrand, N., Manon, S., Sousa, M.J., Côrte-Real, 
M., 2010. Mitochondrial degradation in acetic acid-induced yeast apoptosis: the role of Pep4 and the ADP/ATP carrier. Mol Microbiol. 76, 1398-1410.

Peyerl, F.W., Dai, S., Murphy, G.A., Crawford, F., White, J., Marrack, P., Kappler, J.W., 2007. Elucidation of some Bax conformational changes through crystallization of an antibody-peptide complex. Cell Death Differ. 14, 447-452

Renault, T.T., Manon, S., 2011. Bax: Addressed to kill. Biochimie 93, 1379-1391.

Renault, T.T., Grandier-Vazeille, X., Arokium, H., Velours, G., Camougrand, N., Priault, M., Teijido, O., Dejean, L.M., Manon, S, 2012. The cytosolic domain of human Tom22 modulates human Bax mitochondrial translocation and conformation in yeast. FEBS Lett. 586, 116-121

Renault, T.T., Teijido, O., Antonsson, B., Dejean, L.M., Manon, S., 2013. Regulation of Bax mitochondrial localization by $\mathrm{Bcl}-2$ and $\mathrm{Bcl}-\mathrm{x}(\mathrm{L})$ : keep your friends close but your enemies closer. Int. J. Biochem. Cell. Biol. 45, 64-67

Renault, T.T., Teijido, O., Missire, F., Ganesan, Y.T., Velours, G., Arokium, H., Beaumatin, F., Llanos, R., Athané, A., Camougrand, N., Priault, M., Antonsson, B., Dejean, L.M., Manon, S., 2015. Bcl-xL stimulates Bax relocation to mitochondria and primes cells to ABT-737. Int. J. Biochem. Cell. Biol. 64, 136-146.

Salvador-Gallego, R., Mund, M., Cosentino, K., Schneider, J., Unsay, J., Schraermeyer, U., Engelhardt, J., Ries, J., García-Sáez, A.J. 2016. Bax assembly into rings and arcs in apoptotic mitochondria is linked to membrane pores. EMBO J. 35, 389-401.

Schellenberg, B., Wang, P., Keeble, J.A., Rodriguez-Enriquez, R., Walker, S., Owens, T.W., Foster, F., Tanianis-Hughes, J., Brennan, K., Streuli, C.H., Gilmore, A.P., 2013. Bax exists in a dynamic equilibrium between the cytosol and mitochondria to control apoptotic priming. Mol. Cell 49, 959971.

Simonyan, L., Renault, T.T., da Costa Novais, M.J., Sousa, M.J., Côrte-Real, M., Camougrand, N., Gonzalez, C., Manon, S., 2016. Regulation of Bax/mitochondria interaction by AKT. FEBS Lett. 590, 13-21. 
Subburaj, Y., Cosentino, K., Axmann, M., Pedrueza-Villalmanzo, E., Hermann, E., Bleicken, S., Spatz, J., García-Sáez, A.J. 2015. Bax monomers form dimer units in the membrane that further self-assemble into multiple oligomeric species. Nat. Commun. 6, 8042.

Suzuki, M., Youle, R.J., Tjandra, N., 2000. Structure of Bax: coregulation of dimer formation and intracellular localization. Cell 103, 645-654.

Tang, L., Tron, V.A., Reed, J.C., Mah, K.J., Krajewska, M., Li, G., Zhou, X., Ho, V.C., Trotter, M.J., 1998. Expression of apoptosis regulators in cutaneous malignant melanoma. Clin Cancer Res. 4, 1865-1871.

Teijido, O., Dejean, L. 2010. Upregulation of Bcl2 inhibits apoptosis-driven BAX insertion but favors BAX relocalization in mitochondria. FEBS Lett. 584, 3305-3310.

Todt, F., Cakir, Z., Reichenbach, F., Youle, R.J., Edlich, F., 2013. The C-terminal helix of Bcl-x(L) mediates Bax retrotranslocation from the mitochondria. Cell Death Differ. 20, 333-342.

Tsujimoto, Y., Nakagawa, T., Shimizu, S., 2006. Mitochondrial membrane permeability transition and cell death. Biochim. Biophys. Acta. 1757, 1297-1300.

Ubaidillah, M., Kim, K.A., Kim, Y.H., Lee, I.J., Yun, B.W., Kim, D.H., Loake, G.J., Kim, K.M., 2013. Identification of a drought-induced rice gene, OsSAP, that suppresses Bax-induced cell death in yeast. Mol. Biol. Rep. 40, 6113-6121

Westphal, D., Dewson, G., Menard, M., Frederick, P., Iyer, S., Bartolo, R., Gibson, L., Czabotar, P.E., Smith, B.J., Adams, J.M., Kluck, R.M., 2014. Apoptotic pore formation is associated with inplane insertion of Bak or Bax central helices into the mitochondrial outer membrane. Proc. Natl Acad. Sci. U S A. 111, E4076-E4085.

Wolter, K.G., Hsu, Y.T., Smith, C.L., Nechushtan, A., Xi, X.G., Youle, R.J., 1997. Movement of Bax from the cytosol to mitochondria during apoptosis. J. Cell Biol. 139, 1281-1292.

Xin, M., Gao, F., May, W.S., Flagg, T., Deng, X., 2007. Protein kinase Czeta abrogates the proapoptotic function of Bax through phosphorylation. J. Biol. Chem. 282, 21268-21277. 
Xu, Q., Reed, J.C., 1998. Bax inhibitor-1, a mammalian apoptosis suppressor identified by functional screening in yeast. Mol. Cell 1, 337-346. 


\section{Legends to Figures}

Figure 1. Schematic representation of the classification of Bcl-2 family members and BH3containing proteins.

TOP: Classical representation of the Bcl-2 family members, bases on their function (anti- $v / s$ proapoptotic) and on their structure (multidomain v/s BH3-only).

BOTTOM: Phylogenetic classification based on the evolution of $\mathrm{BH}$ domains . True Bcl-2 homologs include multidomain proteins (anti- and pro-apoptotic) and Bid, that has a structure closely related to that of Bcl-xL (Chou et al., 1999). BH3-domains can be divided into canonical domains, that are evolutionary related to those of Bcl-2 homologs, and non-canonical domains, that might proceed from a convergent evolution (Aouacheria et al., 2013, 2015).

\section{Figure 2. Mitochondrial proteins released during cell death in mammals and yeast.}

TOP: In mammalian cells, Bax/Bak-dependent apoptosis is associated to the formation of a large pore in the MOM, that allows the release of cytochrome c. It remains however unclear if this pore also allows the release of other factors. Necrosis and late apoptosis are associated to the opening of $\mathrm{mPTP}$, that induces a non-selective release of all the factors localized in the intermembrane space. BOTTOM: In yeast, the heterologous expression of Bax is associated to the formation or the same pore as in mammals, supporting that this pore contains Bax (Pavlov et al., 2001). Other factors can be released following death signals specific to yeast, such as acetic acid treatments (Pereira et al., 2010). However, Bax effects in yeast do not depend on these factors (Kissova et al., 2006).

Figure 3. Measurement of Bax-driven release of cytochrome c from yeast mitochondria by redox spectrophotometry and immunoblotting.

Mitochondria were isolated from yeast cells expressing wild-type Bax (BaxWT, poorly active) or a constitutively mitochondrial and active mutant Bax-P168A (Arokium et al., 2004).

LEFT: Redox spectrophotometry measurements. A mitochondrial suspension (3-5mg protein/mL) was placed in the cuvettes of a double-beam spectrophotometer. The reference cuvette was oxidized with potassium ferricyanide and the sample cuvette was reduced with sodium dithionite. The difference spectra were acquired between 500 and 650nm. Cytochrome $\mathrm{c}+\mathrm{c} 1$ and cytochrome $\mathrm{b}$ contents were calculated from the height of the peaks, as indicated, and manually corrected with the difference of the isobestic points at $540 \mathrm{~nm}$ and $575 \mathrm{~nm}$. A molar extinction coefficient of $18,000 \mathrm{M}^{-}$ ${ }^{1} . \mathrm{cm}^{-1}$ for both types of cytochromes was used, and cytochrome $\mathrm{c}$ was calculated by considering that the stoechiometry cytochrome b/cytochrome $\mathrm{c} 1$ is 2 .

RIGHT: Immunoblotting measurements. $100 \mu \mathrm{g}$ of mitochondrial proteins or of post-mitochondrial 
supernatants were blotted, and immunodetected with a custom antibody against yeast cytochrome c. Antibodies against Phosphoglycerate Kinase (Pgk) and subunit 2 of respiratory complex IV (Cox2) were used as loading controls. The immunoblotting against Bax shows that the mutant Bax-P168A is more localized in mitochondria than BaxWT (Renault et al., 2015).

\section{Figure 4. Comparison of the effects of full-length Bcl-xL and truncated Bcl-xL $\Delta C$ on Bax mitochondrial localization.}

LEFT: Bax is under a dynamic equilibrium between mitochondria and cytosol, owing to the processes of $\mathrm{Bcl}-\mathrm{xL}$-driven translocation and retrotranslocation. Mitochondrial Bax is primed but remains inactive because of the interaction with $\mathrm{Bcl}-\mathrm{xL}$. The addition of a $\mathrm{BH} 3$-mimetic (or the expression of a $\mathrm{BH} 3$-only partner) enables the derepression of the interaction and the full activation of Bax.

RIGHT: Bcl-xL $\Delta \mathrm{C}$ stimulates the ttanslocation but not the retrotranslocation, leading to a higher mitochondrial Bax content. Furthermore, the interaction between Bax and Bcl-xL $\Delta \mathrm{C}$ is weak, and Bax can be fully activated without the need of a BH3-mimetic. 


\section{Functional/structural classification}

Antiapoptotic members

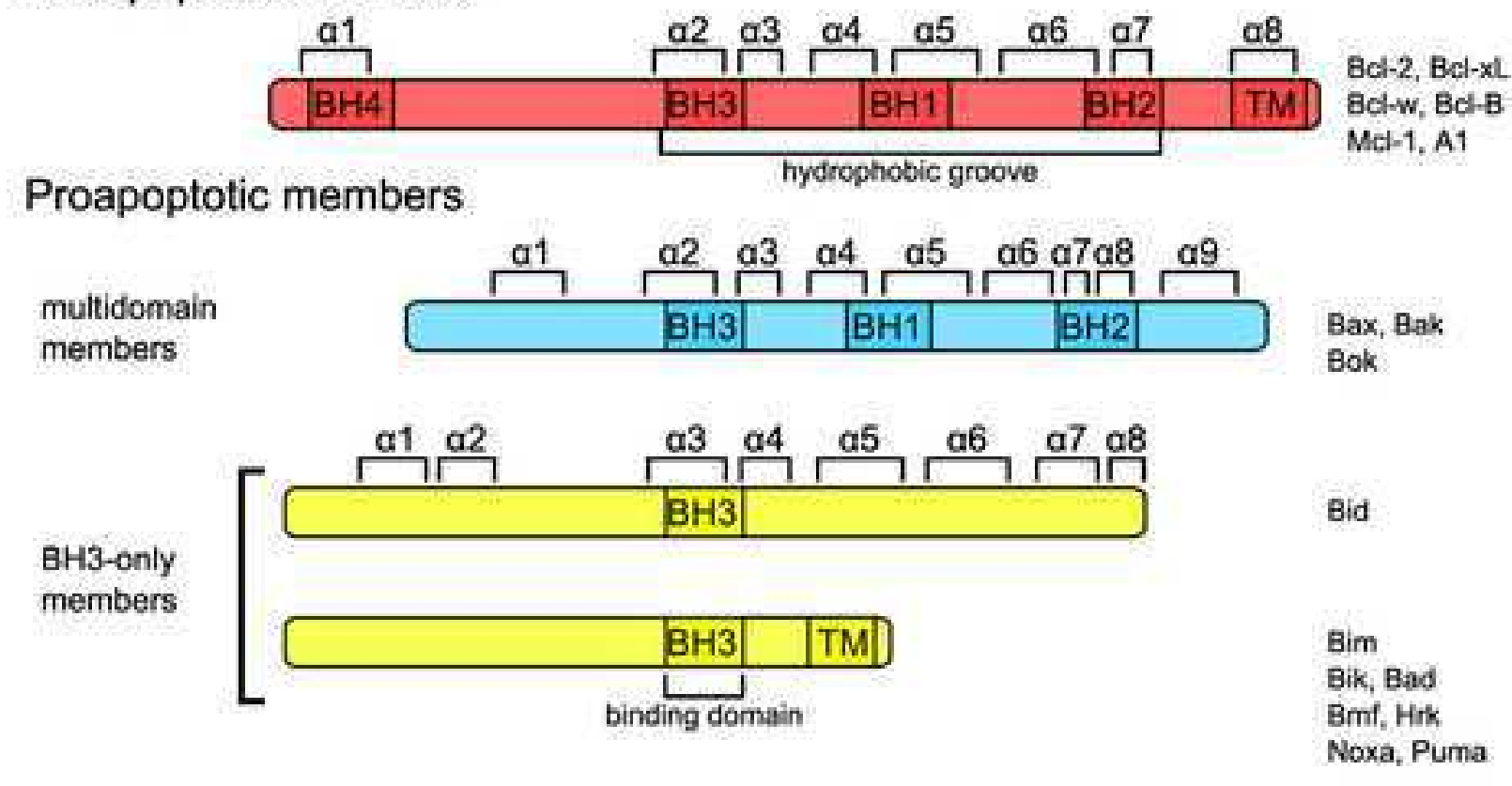

\section{Phylogenetic classification}

$\mathrm{Bcl}-2$ homologs

antiapoptotic

Canonical BH3-domain

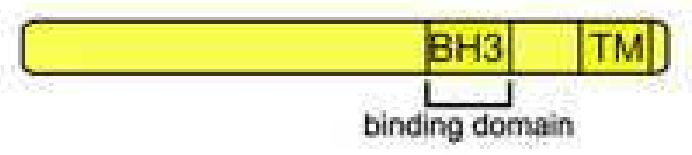

Bim

Bik, Bad

Bmf, Hrk

Noxa, Puma

Non-canonical BH3-domain

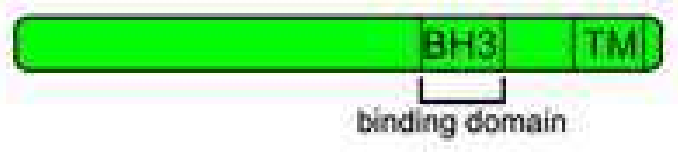

Bnip3L/nix 
Mammals

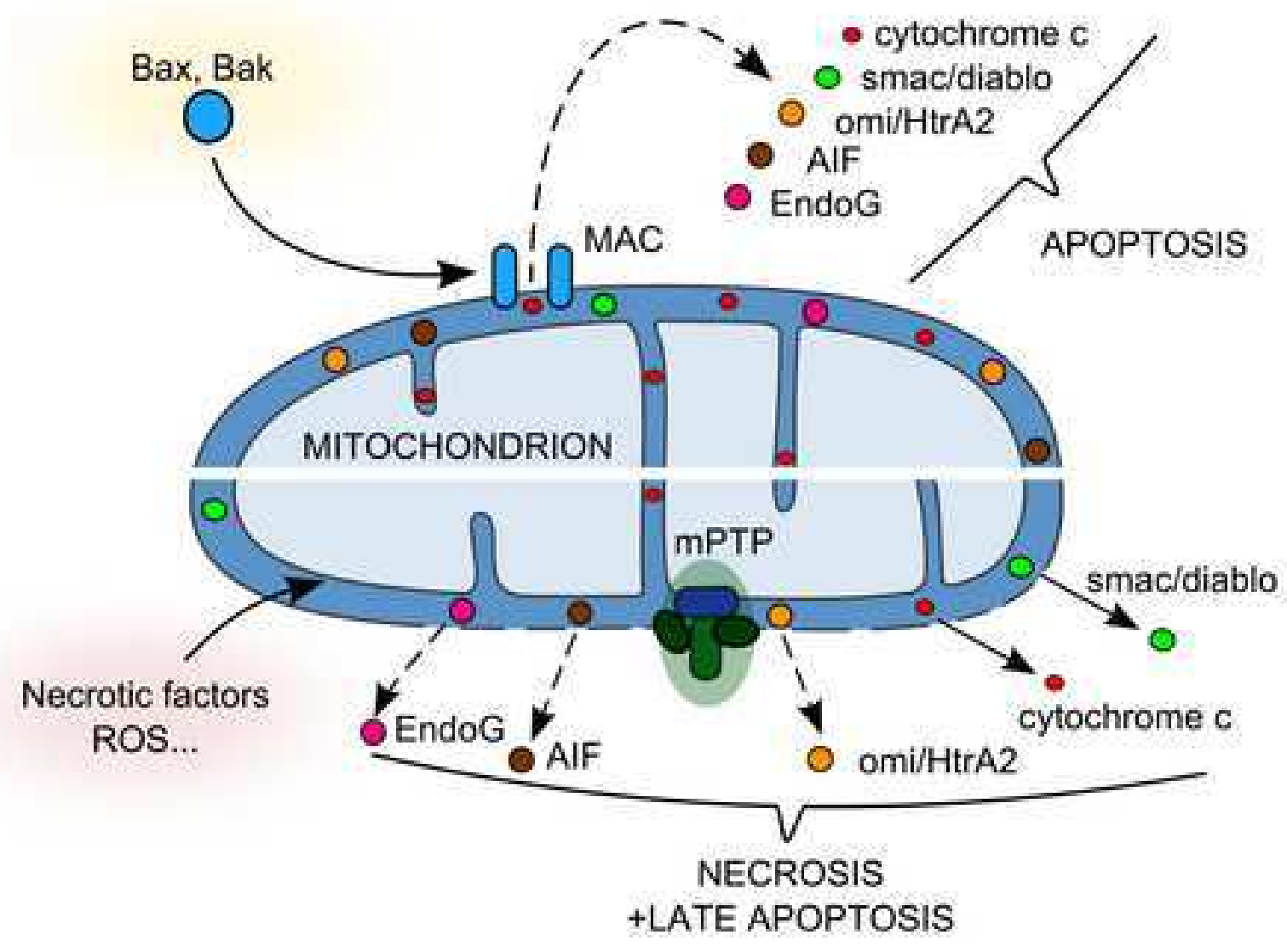

\section{Yeast}

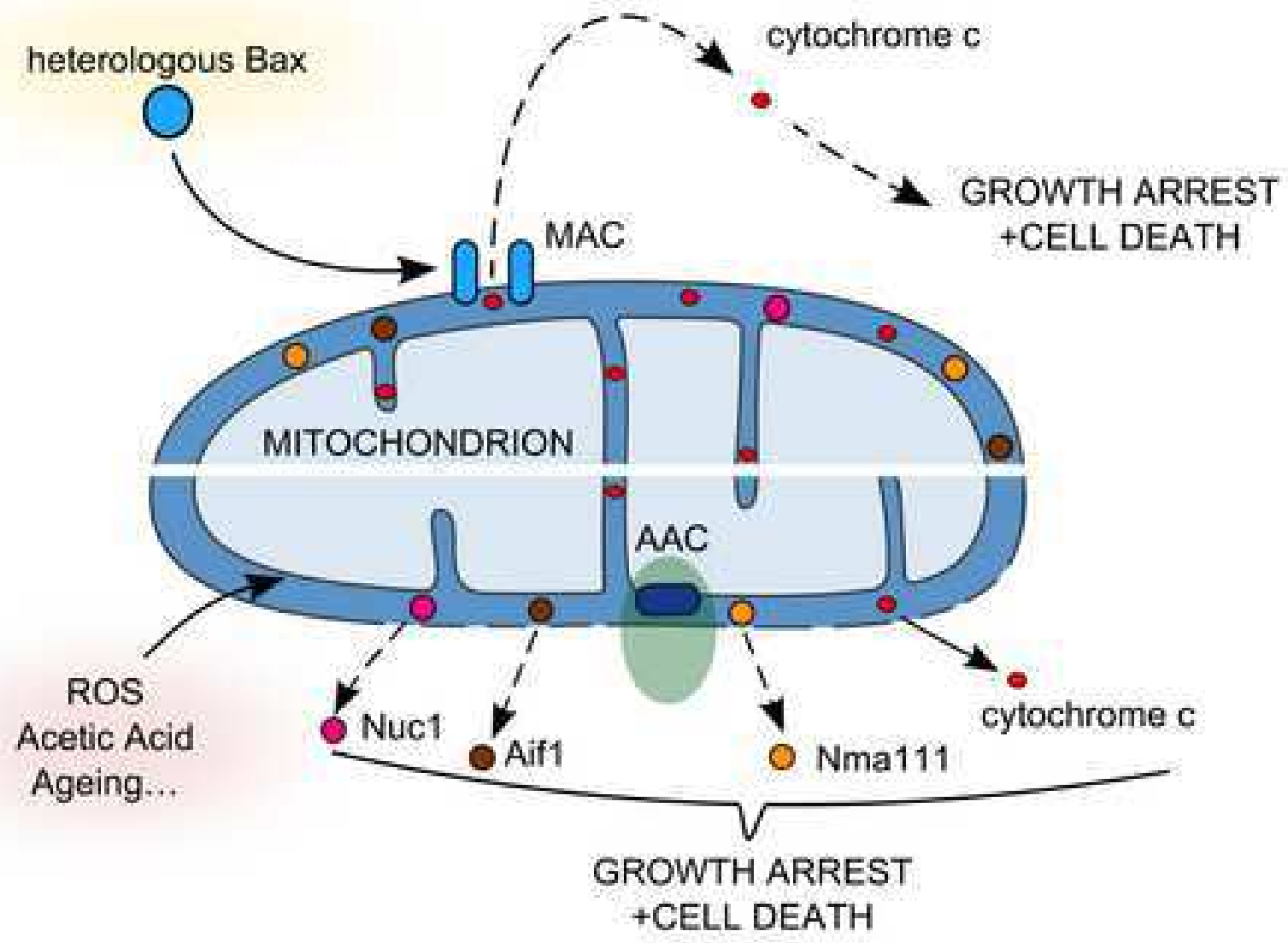




\section{Redox spectrophotometry}
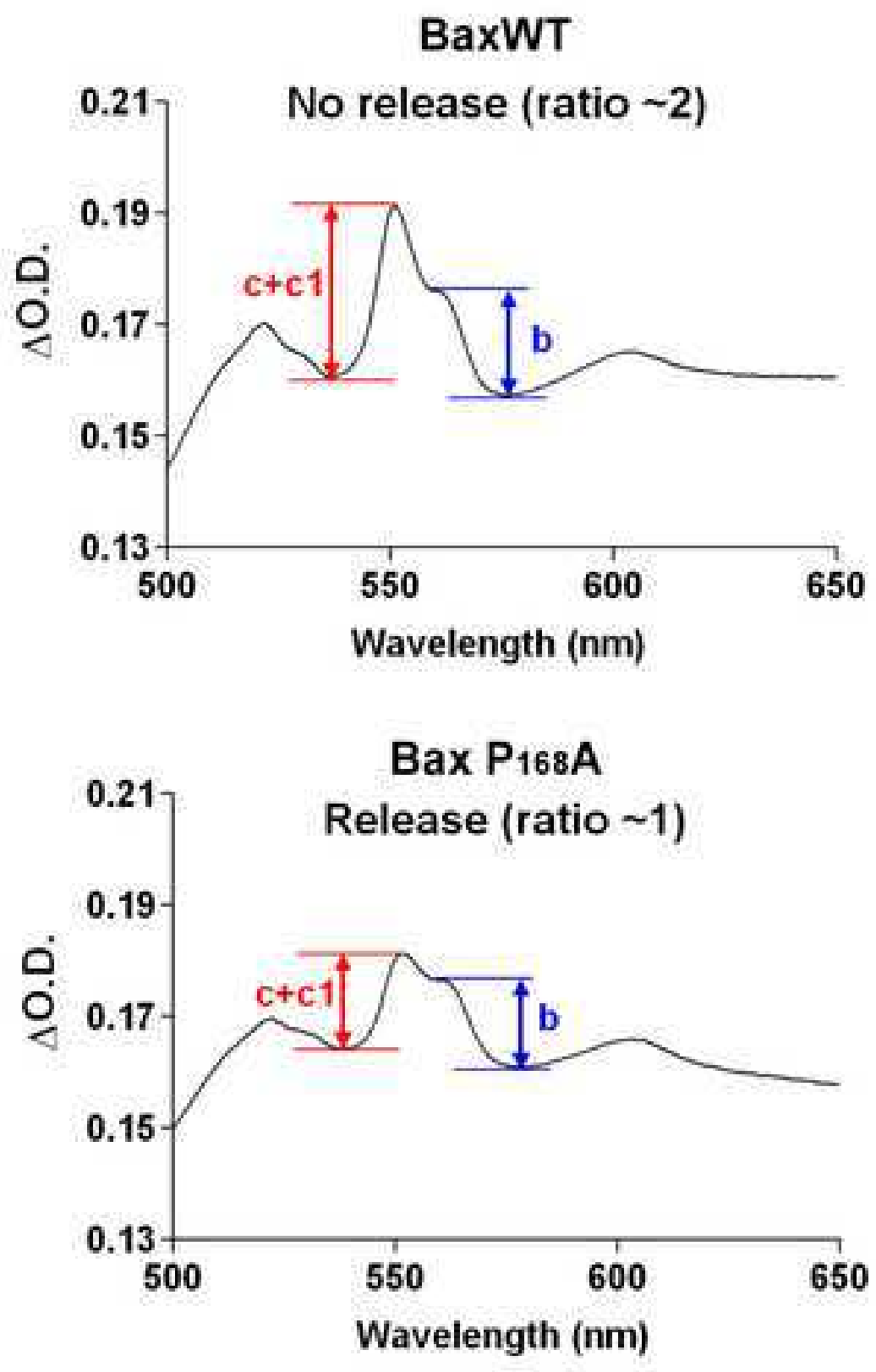

Immunoblotting

\section{Mitochondria}

Bax expressed: WT $P_{168} A$

Bax
Cox2
Cyt.c

Post-mitochondrial supernatants

Bax expressed: - WT $P_{168} \mathrm{~A}$

Cyt.c

Pgk1 


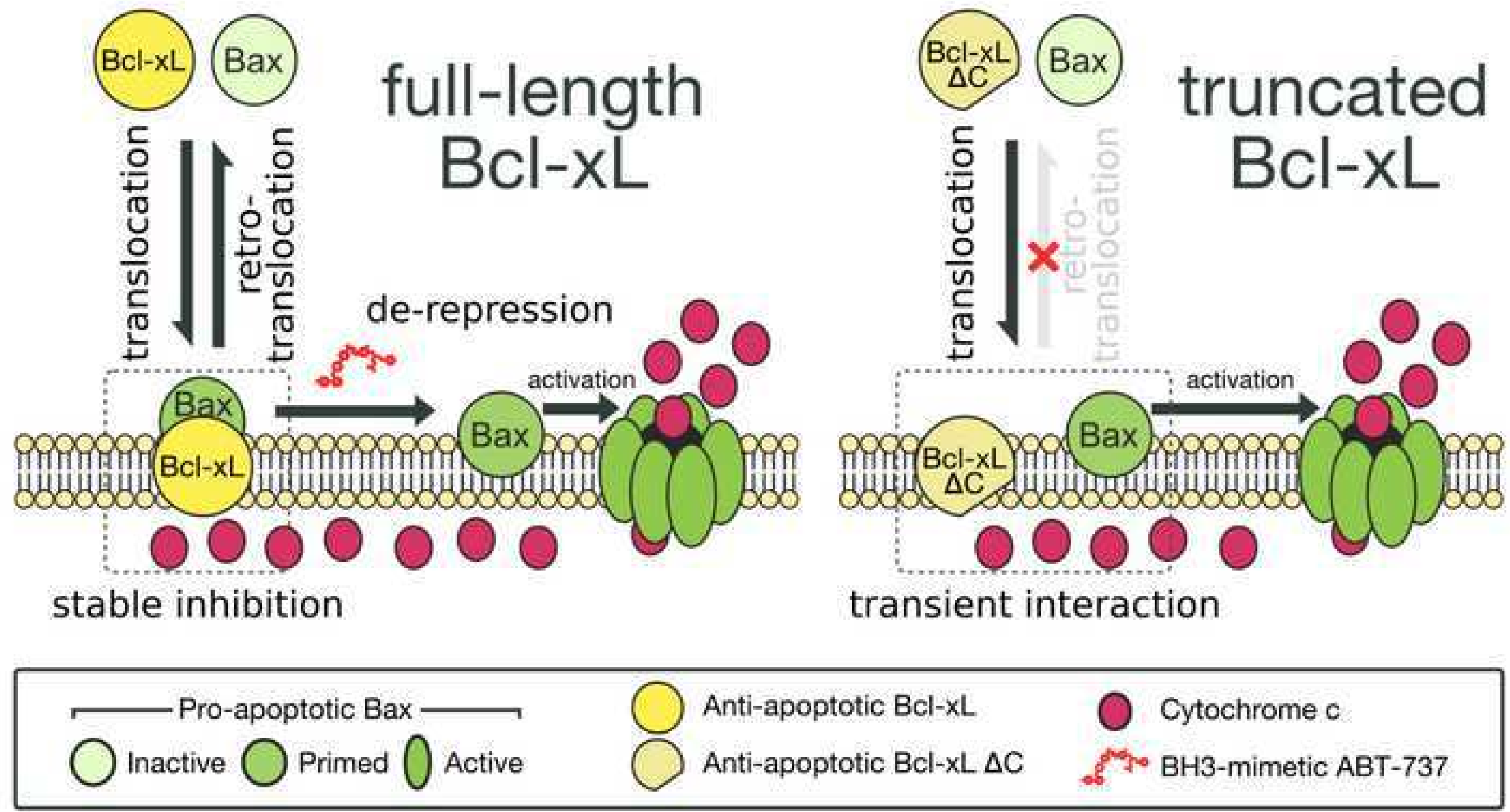




\title{
A brewing understanding of the regulation of Bax function by Bcl-xL and Bcl-2
}

\author{
Thibaud T. Renault ${ }^{1,2}$, Laurent M. Dejean ${ }^{3}$, and Stéphen Manon ${ }^{4,5}$ \\ ${ }^{1}$ Helmholtz Center for Infection Research, Junior Research Group Infection Biology of Salmonella, \\ Inhoffenstraße 7, 38124 Braunschweig, Germany \\ ${ }^{2}$ Max Planck Institute for Infection Biology, Charitéplatz 1, 10117 Berlin, Germany \\ ${ }^{3}$ California State University of Fresno, Department of Chemistry, 2555 E. San Ramon Ave M/S \\ SB70, Fresno, CA 93740-8034, USA \\ ${ }^{4}$ CNRS, UMR5095, 1 Rue Camille Saint-Saëns, 33077 Bordeaux, France \\ ${ }^{5}$ Université de Bordeaux, 146 Rue Léo Saignat, 33076 Bordeaux, France
}

\section{Summary}

Bcl-2 family members form a network of protein-protein interactions that regulate apoptosis through permeabilization of the mitochondrial outer membrane. Deciphering this intricate network requires streamlined experimental models, including the heterologous expression in yeast. This approach had previously enabled researchers to identify domains and residues that underlie the conformational changes driving the translocation, the insertion and the oligomerization of the proapoptotic protein Bax at the level of the mitochondrial outer membrane. Recent studies that combine experiments in yeast and in mammalian cells have shown the unexpected effect of the antiapoptotic protein $\mathrm{Bcl}-\mathrm{xL}$ on the priming of Bax. As demonstrated with the BH3-mimetic molecule ABT-737, this property of Bcl-xL, and of Bcl-2, is crucial to elaborate about how apoptosis could be reactivated in tumoral cells.

\section{1-Introduction: Bcl-2 family members v/s BH3-containing proteins}

Apoptosis is the main type of programmed cell death in animals, participating to the modeling of organs during the development, and to tissue homeostasis during the whole life. It is activated following external or internal stimuli, and leads to a non-inflammatory response, opposite to other forms of cell death, such as necrosis.

It is generally considered that there are two types of apoptotic signaling pathways:

- the exogenous pathway, when death is initiated by the binding of an external ligand to a receptor, involves the direct activation of caspases, a group of proteases responsible for the implementation of apoptotic characteristics; 
- the endogenous pathway, when death is initiated "from the inside", for example through the activation of transcription factor $\mathrm{p} 53$ following an alteration to DNA, involves mitochondria. Alterations of the apoptotic program are associated with major age-related diseases, such as cancers when apoptosis is deficient, or degenerative diseases when apoptosis is over-activated. It is because of the existence of these major health issues that apoptosis is one of the most studied processes of cell biology in the last 20 years. A considerable amount of knowledge has been accumulated about the signaling pathways that regulate cell death, both under physiological and pathological situations. However, it still remains difficult to predict how these pathways modulate the molecular mechanisms underlying apoptosis, because of antagonistic effects between signaling pathways regulating cell death and survival, and the redundancy between parallel pathways. This intricacy is further increased in cell lines, where survival pathways are often over-activated while death pathways are repressed. This is why streamlined experimental models are needed to investigate the link between cellular and molecular regulations.

The group of proteins known as Bcl-2 family members are central players of apoptosis, because they form the interface between the early signaling events engaging the cells into the apoptotic process, and the later events conferring their apoptotic characteristics to the cells, leading to their elimination by the immune system (Adams and Cory, 2007, for a review). Bcl-2 family members are characterized by 4 homology domains, called $\mathrm{BH} 1$ to $\mathrm{BH} 4$. These domains are the keystones of these proteins' function and regulation, as they enable their mutual interaction within an intricate and highly regulated network.

Classically, the Bcl-2 family has been divided into 3 sub-families: anti-apoptotic proteins (e.g. Bcl2, Bcl-xL), pro-apoptotic proteins (Bax, Bak, Bok), and BH3-only proteins (e.g. Bid, Bad, Puma, Bim) (Fig.1). It is noteworthy that, while the two first sub-families are defined on the basis of a well-identified biological function, the last one is defined by default, on the basis of a structural property.

As a matter of fact, recent phylogenetic studies have shown that BH3-domains are present in many proteins other than the Bcl-2 family (Aouacheria et al., 2013) including, for example, the mammalian protein Beclin-1 (Liang et al., 1999), or the yeast protein Ybh3/Bxi1/YNL305C (Cebulski et al., 2011; Buttner et al., 2011). However, those BH3-domains do not derive from a common ancestor, opposite to the canonical BH3 domain of pro- and anti-apoptotic Bcl-2 family members, but rather result from a convergent evolution (Aouacheria et al., 2013). These studies redefined the BH3-domain as a short interacting motif, that is thus not limited to the Bcl-2 family members (Aouacheria et al., 2015). According to these studies, BH3-containing proteins could be re-organized into three categories (Aouacheria et al., 2013) (Fig.1):

- true Bcl-2 homologs, that contain three or four BH domains, and that can be anti-apoptotic (e.g. 
Bcl-2, Bcl-xL) or pro-apoptotic (Bax, Bak, Bok); Bid, which has only the BH3 domain, is considered as a true Bcl-2 homolog because of its overall structural similarity with Bcl-2;

- BH3-only proteins that contain a canonical BH3-domain (e.g. Bad, Puma, Bim);

- BH3-only proteins that contain a non-canonical BH3-domain (e.g. Beclin-1, Bnip3L/Nix, yeast Ybh3).

These studies show that true Bcl-2 homologs are only present in animals: vertebrates (including Bcl-2, Bax, and their homologs in non-mammalian vertebrates), nematode (C.elegans Ced-9) and insects (D.melanogaster Buffy and DeBcl). The same observation can be done for proteins containing a canonical BH3-domain, in vertebrates (including Bid, Puma, Bad) and in the nematode (Egl-1). All the BH3-containing proteins found in non-animal organisms contain a divergent domain, e.g. Ybh3 in the yeast S.cerevisiae, Rad9 in the yeast S.pombe, MCF in the bacterium P.luminescens, and viral proteins such as the protein CORE from the hepatitis $\mathrm{C}$ virus (Aouacheria et al., 2013). These proteins may have a function that is unrelated to the Bcl-2 family. For example, yeast Ybh3/Bxi1/YNL305C is involved in the UPR response and might modulate calcium dynamics (Cebulski et al., 2011), as shown for its bacterial homolog (Chang et al., 2014). However, like all the proteins containing a divergent $\mathrm{BH} 3$-domain, it might be potentially able to bind to Bcl-2 homologs, namely Bax, particularly when it is over-expressed. Conversely, Bcl-2 homologs might regulate the function of proteins containing a divergent $\mathrm{BH} 3$ domain, independently from apoptosis: as an example, it has been proposed that the pro-autophagic function of Beclin-1 is negatively regulated by the overexpression of Bcl-2 (Pattingre et al., 2005), although the effect of Bcl-2 on autophagy might also be indirect (Lindqvist et al., 2014).

\section{2-Bcl-2 family, MOMP and cytochrome c}

Bcl-2 homologs function is essential to the regulation of mitochondrial outer membrane permeabilization (MOMP), the key event irreversibly engaging the cells towards death. Following MOMP, a group of particular proteases, the caspases, are activated. This activation occurs through two processes: (1) procaspases are cleaved into two subunits and reorganized into active heterotetramers and (2) IAPs, a family of caspases inhibitors, are inactivated.

There is now a large consensus among investigators to consider that MOMP is caused by the formation of a large pore in the mitochondrial outer membrane (MOM), that enables the release of several proteins from the mitochondrial intermembrane space to the cytosol. Five of these proteins have been identified as 'apoptogenic factors' and are described below (Fig.2):

- Cytochrome c $(12.5 \mathrm{kDa})$ is a central soluble component of the electron transport chain; when released, it binds to Apaf-1, forming a complex that catalyzes the cleavage and the activation of caspase-9. 
- Smac/Diablo (25kDa) binds to IAPs, promoting their degradation, and thus preventing the inhibition of caspases.

- Omi/HtrA2 $(49 \mathrm{kDa})$ is a protease that inactivates IAPs.

- Endonuclease G (28kDa) participates to chromatin degradation.

- Apoptosis-Inducing Factor (AIF, 61kDa) is a redox protein that participates to the regulation of the respiratory chain. During apoptosis, it participates to chromatin condensation, but its precise function remains elusive.

It is still unclear whether these proteins, that have different sizes, are released simultaneously and through the same mechanism. Indeed, most studies are done on cultured cells with a sustained apoptotic trigger (such as the addition of an antitumoral drug). Under these conditions, apoptosis is followed by necrosis.

The initial steps of apoptosis might only involve a limited MOMP, without alteration of the inner mitochondrial membrane (see below). On the opposite, the secondary necrotic process might be associated to the activation of the large unselective channel called the mitochondrial Permeability Transition Pore (mPTP), that induces the permeabilization of the inner mitochondrial membrane (Bernardi et al., 2015, for review). This is followed by a massive mitochondrial swelling leading to the unselective rupture of the MOM, and the release of the whole intermembrane space content into the cytosol (Fig.2). Consequently, the mechanistic aspects of selective MOMP should be studied at the early stages of the apoptotic process, when mPTP is still close.

Electrophysiological studies on MOM from apoptotic cells showed the presence of a large conductance channel, that also appeared in the MOM from yeast cells expressing human Bax (Pavlov et al., 2001), or on isolated membranes incubated with Bax oligomers (Dejean et al., 2005). Interestingly, the size of this channel was sufficient to transport cytochrome c $(12.5 \mathrm{kDa})$, but not to transport a bigger protein, such as hemoglobin tetramer $(60 \mathrm{kDa})$ (Dejean et al., 2005). Electrical properties of this channel showed the existence of different conductance substates, suggesting a process of stepwise Bax oligomerization (Martinez-Caballero et al., 2010). Recent studies showed that Bax oligomers form large ring-like structures in the MOM that could be assimilated to the pore of the MOMP machinery (Große et al., 2016; Salvador-Gallego et al., 2016).

Among the apoptogenic factors, cytochrome $\mathrm{c}$ is one of the most ubiquitous and conserved proteins in the whole living world (Margoliash and Fitch, 1968), a feature most certainly related to its central function as a mobile electron carrier that shuttles between respiratory complexes. As such, it can serve as a universal marker for MOMP, including in model systems that do not carry out canonical apoptosis. Most specifically, the release of cytochrome c became a standard in studies regarding the function of animal Bcl-2 homologs after they are expressed in yeast (Fig.3). The expression of human Bax was shown to promote the release of cytochrome $\mathrm{c}$ in yeast (Manon et al., 1997) even 
before it was shown in human cells (Jurgensmeier et al., 1998). Like in mammalian cells, several death signals in yeast, such as acetic acid treatment, induce dramatic mitochondrial morphological alterations and a non-selective release of intermembrane space proteins, that have homologies with mammalian apoptogenic factors (Eisenberg et al., 2007; Cheng et al. 2008; Pereira et al., 2008, for reviews) (Fig.2). Interestingly, Bax effects in yeast do not depend on other proteins that are released following death stimuli (Kissova et al., 2006), such as acetic acid treatment, that may induce a necrotic type of death depending on massive mitochondrial permeabilization resembling $\mathrm{mPTP}$ (Pereira et al., 2010). This supports the view that, in mammalian cells, only cytochrome would be released through Bax-formed channels, while other apoptogenic factors would be released through other systems, such as mPTP (Kroemer et al., 2007, for review) or ceramides channels (Colombini, 2010, for review).

Due to the ease to obtain large amounts of yeast biomass, cytochrome c can be easily quantified by redox spectrophotometry, and compared to non-released cytochromes, such as cytochrome $b$, a membrane-inserted component of respiratory complex III (Fig.3). This allowed measuring the activities of different Bax mutants, with more precision than western-blots quantification (Arokium et al., 2004, 2007; Renault et al., 2015). Furthermore, redox spectrophotometry measures the mitochondrial cytochrome c content after it has been assembled with heme in the mitochondrial intermembrane space (Gonzalez and Neupert, 1990), thus limiting the quantification to cytochrome $\mathrm{c}$ that has transited through mitochondria. On the opposite, western-blots against cytochrome $\mathrm{c}$ also reveal the heme-free apoprotein, before it has been assembled within the mitochondria, meaning that a deficient addressing might be erroneously taken for an increased release.

The redox spectrophotometry measurement of cytochrome $\mathrm{c}$ in yeast mitochondria, following the heterologous expression of human Bax mutants has provided a considerable amount of data about the domains, residues, and possible partners involved in Bax ability to interact with MOM and to release cytochrome c. For example, the consequences of the replacements of Proline residues at positions 8, 13 and 168 by smaller and more flexible Glycine/Alanine residues have pointed out the role of the mobility of the N-terminal unstructured domain and of the C-terminal $\alpha$-helix in Bax activation (Arokium et al., 2004). Electric charge inversions at different positions (Arg9/Asp154) confirmed that favoring the movement of these domains (by disrupting salt bridges), was sufficient to promote the localization of Bax to the MOM (Arokium et al., 2007). Furthermore, this method has allowed evidencing the involvement of the mitochondrial receptor Tom 22 in the adequate translocation of Bax (Bellot et al., 2007; Renault et al., 2012), and the direct activation of Bax by BH3-only proteins tBid (Gonzalves et al., 2005) and Puma (Gallenne et al., 2009). This method has thus proved to be an adequate measurement of the ability of Bax to permeabilize the MOM.

In parallel, Bax expression in yeast induces a reduction of yeast growth and a loss of viability. 
However, these phenotypes involve additional effects beyond the release of cytochrome c, and are

consequently less precise reporters of Bax effects on mitochondria than the direct measurement of cytochrome $\mathrm{c}$ release (Kissova et al., 2006). Nevertheless, they proved their usefulness for the rapid screening of factors that potentially modulate the effects of Bax (Xu and Reed, 1998; Pan et al., 2001; Laloux et al., 2010; Ubaidillah et al., 2013).

\section{3-Bax retrotranslocation}

For long, it had been considered that Bax translocation from the cytosol to the mitochondria was a unidirectional process. This came from the observation that, in non-apoptotic cells, Bax localization is essentially diffuse in the cytosol while, after apoptosis is triggered, it is relocated to mitochondria (Wolter et al., 1997) to form membrane-inserted oligomers that are responsible for MOMP (Antonsson et al., 2000, 2001). Since this process involves major conformational changes (Suzuki et al., 2000; Peyerl et al., 2007), it was hardly conceivable that these oligomers could be disassembled, and that Bax could go back to its previously inactive state in the cytosol. However, significant observations suggested that the passage from soluble/monomeric Bax to membraneinserted/oligomeric Bax is not a one-step process. For example, it has been shown that, during anoikis, Bax could be relocalized to mitochondria, but that the process was reversible (Owens et al., 2009). This, and other experiments, demonstrated that 'mitochondrial Bax' was not obligatorily 'membrane-inserted' Bax (Renault et al., 2013).

Structural studies have allowed designing a complex Bax mutant that has a constitutive mitochondrial localization but that cannot support the conformational change associated to the oligomerization, thus remaining incompetent for cytochrome $\mathrm{c}$ release. Under oxidative conditions, this mutant displays two internal disulfide bonds that constraint helices $\alpha 1$ and $\alpha 2$, and $\alpha 1-\alpha 2$ loop and $\alpha 6$, therefore blocking the 'opening' of Bax structure associated to its activation (Edlich et al., 2011). When expressed in HCT-116 or HeLa cells, a GFP-tagged version of this mutant displayed a mitochondrial localization and did not trigger apoptosis, as expected. Following the photobleaching of GFP fluorescence in cell nuclei, both nuclear and cytosolic fluorescence disappeared while mitochondrial fluorescence remained. This reflected the rapid dynamics of exchange between the nucleus and the cytosol, and its absence for mitochondrial Bax. However, by following the reappearance of the fluorescence in the cytosol, the authors showed that a fraction of mitochondrial Bax could be retrotranslocated from the mitochondria to the cytosol. Most interestingly, this retrotranslocation process was greatly accelerated when the anti-apoptotic protein $\mathrm{Bcl}-\mathrm{xL}$ was overexpressed (Edlich et al., 2011). This led the authors to conclude that, in non-apoptotic cells, (1) Bax subcellular localization followed a dynamic equilibrium between mitochondria and cytosol and that (2) anti-apoptotic proteins could displace this equilibrium towards a more cytosolic localization. An 
additional interesting observation was that a mutant of Bcl-xL deleted of the C-terminal $\alpha$-helix

$(\mathrm{Bcl}-\mathrm{xL} \Delta \mathrm{C})$ was unable to promote Bax retrotranslocation, and further experiments demonstrated that the deletion of the 4 last residues of Bcl-xL were sufficient to prevent it (Todt et al., 2013). The question remained whether this process was only dependent on the intrinsic properties of interaction between the two proteins, or also involved external factors (such as, for example, the presence of other Bcl-2 family members). Since yeast does not contain endogenous Bcl-2 family members, it is a powerful tool to answer this question. Bax was expressed alone, or co-expressed with full-length $\mathrm{Bcl}-\mathrm{xL}$ or truncated $\mathrm{Bcl}-\mathrm{xL} \Delta \mathrm{C}$ in a yeast mutant inactivated for the major vacuolar protease Pep4p (the yeast ortholog of cathepsin D), and in the presence of the general inhibitor of serine-proteases PMSF. Under these conditions, following the addition of an inhibitor of protein synthesis (cycloheximide), the cellular Bax content remained stable for at least 4 hours. Mitochondria were then isolated to measure the evolution of Bax mitochondrial content following cycloheximide addition. Since the total content was stable, any decrease of the mitochondrial content would indicate retrotranslocation. When expressed alone, mitochondrial Bax levels remained constant. When co-expressed with Bcl-xL, mitochondrial Bax levels were decreased by $50 \%$ within 2 hours. When co-expressed with Bcl-xL $\Delta \mathrm{C}$, mitochondrial Bax levels remained constant. Similar experiments were done in mouse pro-lymphocytic cells FL5.12, with the same results, showing that the experiment in yeast actually led to observations relevant to mammalian physiology. These results were therefore consistent with the hypothesis that Bcl-xL (but not Bcl$\mathrm{xL} \Delta \mathrm{C}$ ) was able to promote the retrotranslocation of Bax, when the two proteins were co-expressed in yeast. This demonstrated that the retrotranslocation of Bax by Bcl-xL was only dependent on molecular properties of $\mathrm{Bax}$ and $\mathrm{Bcl}-\mathrm{xL}$, without interference from factors present in mammalian cells and absent from yeast, such as other Bcl-2 family members (Renault et al., 2015). Importantly, no retrotranslocation was observed when a constitutively active mutant of Bax, carrying a substitution P168A (Arokium et al., 2004; Cartron et al., 2005) was used. This supports the view that, once it is inserted and oligomerized (since it is able to promote the release of cytochrome c), Bax cannot be retrotranslocated.

\section{4-Steady-state Bax subcellular localization}

Intuitively, the existence of Bax retrotranslocation suggests that, in the presence of Bcl-xL, the steady-state Bax localization should be more cytosolic than when Bax is expressed alone. This can be correlated with the classical view of over-expressed Bcl-xL (or Bcl-2) sequestering Bax away from mitochondria, thus preventing apoptosis by restraining Bax ability to reach and permeabilize MOM.

Opposite to this prediction, we observed that the over-expression of Bcl-xL or of Bcl-2 increased 
the mitochondrial localization of endogenous Bax in FL5.12 cells (Teijido and Dejean, 2010;

Renault et al., 2015). Strikingly, Bax mitochondrial content reached the same level as measured in parental cells committed to apoptosis through IL-3 removal. Although less marked, a similar effect was observed in HCT-116 cells overexpressing Bcl-xL, showing that it was not a unique property of FL5.12 cells.

We then investigated if this apparently paradoxical effect of Bcl-xL on Bax mitochondrial localization was only dependent on the interaction between $\mathrm{Bax}$ and $\mathrm{Bcl}-\mathrm{xL}$ or if other factors were involved, by doing the experiments in yeast. We observed that Bax mitochondrial content was increased when Bcl-xL was co-expressed with Bax in yeast. This last result showed that Bcl-xLmediated Bax increase at the mitochondria was a general phenomenon, that depended only on Bax and Bcl-xL.

Most interestingly, we observed that the co-expression of $\mathrm{Bcl}-\mathrm{xL} \Delta \mathrm{C}$ induced an even higher increase of Bax mitochondrial localization in FL5.12 cells, in HCT-116 cells, and in yeast (Renault et al., 2015). As discussed above, truncated Bcl-xL $\Delta \mathrm{C}$ is not able to promote Bax retrotranslocation. This suggests that $\mathrm{Bcl}-\mathrm{xL}$ regulates Bax mitochondrial localization through two opposed processes: retrotranslocation, for which $\mathrm{Bcl}-\mathrm{xL} \Delta \mathrm{C}$ is impaired, and translocation, promoted both by full-length Bcl-xL and truncated Bcl-xL $\Delta \mathrm{C}$ (Fig.4).

\section{5-Bax priming is enhanced in cells overexpressing Bcl-xLAC or Bcl-xL}

The immediate consequence of the increase in the steady-state level of mitochondrial Bax is a potentially higher ability to initiate apoptosis. However, the presence of Bcl-xL, and the interaction between the two proteins, obviously prevent Bax activation. This can be verified by the fact that IL-3 removal induced a lower level of apoptosis in Bcl-xL-overexpressing FL5.12 cells, than in parental cells. Here again, the inhibition only depends on the interaction between Bax and Bcl-xL since, in yeast, the effect of a constitutive mitochondrial and active mutant of Bax on mitochondrial permeabilization is also prevented by the co-expression of Bcl-xL.

On the other hand, the overexpression of Bcl-xL $\Delta \mathrm{C}$ does not prevent the apoptosis of FL5.12 cells induced by the removal of IL-3, and does not prevent the permeabilization of yeast mitochondrial membrane by a constitutively active Bax mutant. In line with these observations, coimmunoprecipitation assays showed that the interaction between $\mathrm{Bax}$ and $\mathrm{Bcl}-\mathrm{xL} \Delta \mathrm{C}$ was not detectable under conditions where the one between Bax and full-length $\mathrm{Bcl}-\mathrm{xL}$ was. This demonstrates that the presence of the $\mathrm{C}$-terminal $\alpha$-helix of $\mathrm{Bcl}-\mathrm{xL}$ is required for a stable interaction and subsequent efficient inhibition of Bax.

Furthermore, we observed that the expression of Bcl-xL $\Delta \mathrm{C}$ stimulated Bax-driven MOMP in yeast. This rather unexpected effect was dependent on the interaction between the two proteins, since it 
was abrogated by introducing the canonical G138A mutation in the BH1-domain of Bcl-xL $\Delta \mathrm{C}$ (Renault et al., 2015), that is known to prevent the interaction between the two proteins (Ottilie et al., 1997).

These results showed that, although it might not be stable enough to be detectable by coimmunoprecipitation, a transient interaction between $\mathrm{Bax}$ and $\mathrm{Bcl}-\mathrm{xL} \Delta \mathrm{C}$ occurs and is sufficient to increase mitochondrial Bax content, but is not sufficient to prevent Bax-induced permeabilization. This was not observed with full-length Bcl-xL since its interaction with Bax, while inducing translocation of the pro-apoptotic protein, was stable enough (detectable by coimmunoprecipitation, as a matter of fact) to also keep it inactive.

Since Bcl-xL $\Delta \mathrm{C}$ is not a natural variant of the protein, we searched for experimental conditions which could reveal that full-length Bcl-xL is also able to prime Bax. Experiments on purified recombinant proteins had previously shown that the binding, then release, of Bax and Bcl-xL could initiate the active conformation of Bax that can be detected with the 6A7 monoclonal antibody (Hsu and Youle, 1997). The release could be induced by peptides corresponding to the BH3-domain of canonical BH3-only proteins, such as Puma, or by BH3-mimetic molecules such as ABT-737 (Gautier et al., 2011).

Therefore we used ABT-737 to disrupt Bax/Bcl-xL interaction both in the FL5.12 and the yeast models. The addition of ABT-737 to parental FL5.12 cells did not induce apoptosis, consistently with previous works (Certo et al., 2006). On the opposite, the addition of ABT-737 to FL5.12 cells overexpressing Bcl-xL induced a significant level of apoptosis (Renault et al., 2015).

We observed that ABT-737 had no effect on the biomass of yeast cells expressing Bax alone, or Bcl$\mathrm{xL}$ alone, but it significantly decreased the biomass of cells co-expressing Bax and Bcl-xL. Although this result might not rely only on Bax-induced MOMP, for the reasons discussed above (Kissova et al., 2006), it is nevertheless in accordance with the effect of ABT-737 observed in FL5.12 cells.

These experiments show that, both in FL5.12 cells and in yeast, the transient interaction between Bax and Bcl-xL followed by the release of the interaction, promotes the activation of Bax, like previously reported using pure recombinant proteins. Also, the study of yeast cells co-expressing $\mathrm{Bax}, \mathrm{Bcl}-\mathrm{xL}$ (or Bcl-2) and BH3-only proteins, have suggested that the lasts could only activate Bax indirectly, through the inhibition of Bcl-xL or Bcl-2 (Gerecova et al., 2013). A sequential expression of $\mathrm{Bax}$ and $\mathrm{Bcl}-\mathrm{xL} / \mathrm{Bcl}-2$, then $\mathrm{BH} 3$-only proteins, could provide a mean to study whether a given BH3-only protein is able or not to promote the release of Bax under an active conformation. Considering the hypothesis proposed above, this should happen with all the BH3-only proteins, with small efficiency differences due to their higher or lower specificity towards Bcl-2 or Bcl-xL. This has interesting consequences on the potential efficiency of BH3-mimetic molecules in anti- 
tumoral therapy. These molecules were designed to prevent the inhibition of apoptosis by anti-

apoptotic Bcl-2 family members (essentially Bcl-2, Bcl-xL, and Mcl-1), that are overexpressed in most cancer cells (see e.g. Tang et al., 1998; Pena et al., 1999, Castilla et al., 2006). The fact that, by breaking the interaction between Bax and Bcl-2/xL, not only they liberate Bax, but they further activate it, renders these molecules even more desirable as anti-tumor therapy, provided that Bax is still expressed and not mutated.

\section{6-A correlation between Bax phosphorylation and its interaction with Bcl-xL?}

From the discussion above, Bcl-xL is able to stimulate both Bax translocation to the MOM, and Bax retrotranslocation to the cytosol. This might appear like a futile cycle, but actually results in a high turnover of Bax localization and, as we have observed, a high mitochondrial content of 'primed' Bax, ready to trigger apoptosis. This might make the system more reactive than if Bax was only sequestered away from mitochondria, since Bax is already on target, ready to be activated after the release of its interaction with $\mathrm{Bcl}-2 / \mathrm{Bcl}-\mathrm{xL}$. However, the efficiency of such a 'dynamic cycling' model implies that the interaction between Bax and Bcl-xL has different properties depending if it happens in the cytosol or in the MOM. This may rely on biochemical differences between cytosolic and mitochondrial Bax.

Bax phosphorylation on different residues has been observed by several groups (Gardai et al., 2004; Linseman et al., 2004; Xin et al., 2007). Two main residues, S163 and S184, are substrates of kinases, although this does not exclude that other residues could be targeted as well. S163 is phosphorylated by GSK3 $\beta$. This implies that T167 should also be phosphorylated, since the consensus site for GSK3 $\beta$ is $\operatorname{SxxxT}_{\mathrm{P}}\left(\mathrm{S}_{\mathrm{P}}\right)$. S184 is the target of different kinases, including AKT and

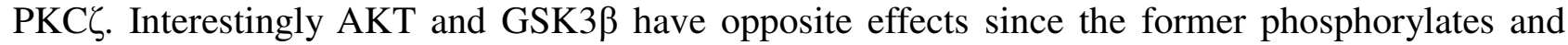
inactivates the later. Furthermore, AKT is generally involved in survival signaling pathways, while GSK3 $\beta$ is involved in death pathways (Martini et al., 2014), making their opposite effects on Bax rather predictable.

The heterologous expression of phosphomimetic and non-phosphorylatable mutants of S163 and S184 in yeast suggests that modifications of these residues participate to the regulation of the interaction of Bax with mitochondria (Arokium et al., 2007; Simonyan et al., 2016). When present alone, the mutation S163D does not have any particular phenotype, but it can activate Bax when it is combined to other mutations that facilitate intramolecular movements (Arokium et al., 2007).

The phosphorylation of S184 has attracted much interest because it is located in the C-terminal $\alpha$ helix, of which the movement is crucial to initiate Bax relocalization. It had been shown that the phosphorylation of S184 retained Bax away from mitochondria, while its dephosphorylation has the opposite effect (Gardai et al., 2004). This could be reproduced in yeast where the mutants S184A/V 
have a higher mitochondrial localization than the mutant S184D (Arokium et al., 2007; Simonyan et

al., 2016). However, this did not fully correlate with the ability of these mutants to induce MOMP. Indeed, the mutant S184D was surprisingly more efficient than mutants S184A/V (and wild-type Bax), to promote the release of cytochrome $\mathrm{c}$. These results suggest that the intrinsic capacity of the phosphomimetic mutant to induce MOMP was higher than that of the non-phosphorylatable mutant, that was apparently in contradiction with the fact that Bax phosphorylated on S184 is less able to induce apoptosis than the non-phosphorylated protein (Gardai et al., 2004). Part of the answer to this paradox might be related to the fact that, in mammalian cells, Bax is not expressed alone, but in the presence of, namely, anti-apoptotic proteins. Bax phosphomimetic and non-phosphorylatable mutants were then co-expressed with full-length Bcl-xL or truncated Bcl-xL $\Delta \mathrm{C}$ (Simonyan et al., 2016). We observed that the mitochondrial localization of the phosphomimetic mutant S184D did not differ from that of wild-type Bax, with an increase induced by Bcl-xL and a further increase induced by $\mathrm{Bcl}-\mathrm{xL} \Delta \mathrm{C}$, linked to the absence of retrotranslocation, as described above. Interestingly, the behavior of the non-phosphorylatable mutant S184A differed: its mitochondrial content was increased by Bcl-xL, like that of wild-type Bax and of the phosphomimetic mutant S184D, but it was not further increased, and was even about twice less increased, by Bcl-xL $\Delta \mathrm{C}$. Since the major difference between full-length $\mathrm{Bcl}-\mathrm{xL}$ and truncated $\mathrm{Bcl}-\mathrm{xL} \Delta \mathrm{C}$ is their capacity to retrotranslocate Bax, this result showed that retotranslocation did not have any effect on the mitochondrial localization of the non-phosphorylatable mutant Bax-S184A (Simonyan et al., 2016). This suggests that the ability of Bax to be retrotranslocated might depend on its phosphorylation, namely on S184. In mammalian cells, a correlation between the phosphorylation of S184 and the retrotranslocation of Bax by Bcl-xL had also been observed (Schellenberg et al., 2013): indeed, a mutant GFP-BaxS184V was retrotranslocated slower than GFP-BaxWT, paralleling the observations in yeast discussed above. Also, the overexpression of AKT stimulated GFP-BaxWT retrotranslocation. However, it was not mentioned whether the overexpression of AKT had or not an effect on the retrotranslocation of GFP-Bax-S184V, and it cannot be yet ascertained that this effect of AKT and the consequence of the phosphorylation of S184 on Bax retrotranslocation are strictly correlated. It should be noted that, when Bax and AKT were co-expressed in yeast, not all the effects of AKT were abolished by the substitution S184V, suggesting that part of the effect of AKT may occur through the phosphorylation of an additional residue besides S184 (Simonyan et al., 2016).

\section{7-Bcl-xL v/s Bcl-2}

Before Bcl-xL, the overexpression of $\mathrm{Bcl}-2$ had been shown to increase the mitochondrial localization of Bax in non-apoptotic FL5.12 cells (Teijido and Dejean, 2010). However, in spite of this apparent similarity, the consequences of Bcl-xL or Bcl-2 overexpression on Bax conformation 
were clearly distinct. Both proteins induced the conformational change of the N-terminus, leading

to a recognition by the $6 \mathrm{~A} 7$ antibody, and reveal the association of Bax to the MOM. But, while the overexpression of Bcl-2 also favored the formation of Bax oligomers (Teijido et al., 2010), the overexpression of Bcl-xL did not (Renault et al., 2013, 2015). It is yet difficult to draw any definitive conclusion about the consequences of this difference. Indeed, under both conditions, Bax remains inactive, being inhibited by its anti-apoptotic partner, and no MOMP was observed. But these observations emphasize the view that the overexpressions of Bcl-2 and Bcl-xL are not identical, considering their respective effects on Bax. This might be a crucial consideration for attempting to re-activate apoptosis in Bcl-2- or Bcl-xL-overexpressing tumoral cells.

Recent structural data brought major advances in the knowledge of Bax organization in the outer mitochondrial membrane. The interaction of $\operatorname{Bax} \Delta \mathrm{C}$ (deprived of its $\mathrm{C}$-terminal hydrophobic $\alpha$ helix) with the BH3 domain of Bid favors the formation of a symmetrical Bax dimer, in which helices $\alpha 5$ and $\alpha 6$ would first lay flat on the membrane instead of being inserted as a hairpin, and then would arrange a large pore by tilting in the membrane (Czabotar et al., 2014: Westphal et al., 2014). The formation of the pore as a juxtaposition of dimers has been proposed as an alternative to the membrane-inserted $\alpha$-helices (Bleicken et al., 2014; Subburaj et al., 2015). This model is compatible with recent microscopy images showing the ring-like organization of $\mathrm{Bax}$ in mitochondria of apoptotic cells (Salvador-Gallego et al., 2016; Große et al., 2016). It is also compatible with electrophysiological data suggesting that the pore formed by Bax have different incremental sizes (Martinez-Caballero et al., 2009).

In non-apoptotic FL5.12 cells overexpressing Bcl-2, the presence of oligomers similar in size to those observed in apoptotic cells have been observed (Renault et al., 2013), while no oligomer was detected in the same cells overexpressing Bcl-xL (Renault et al., 2015). By correlating these observations to the structural model of Bax oligomers, one could speculate that Bcl-2 would favor the formation of Bax oligomers that remain lain on the membrane, while $\mathrm{Bcl}-\mathrm{xL}$ prevents the formation of oligomers, maybe by stabilizing Bax dimers. In any case, the rupture of the interaction between Bax and its anti-apoptotic partner would be sufficient to promote the organization of the pore-forming oligomer.

\section{8-Concluding remarks}

The intrinsic pathway of apoptosis, that involves mitochondria, is triggered by signals originating within the cell, such as, typically, p53 expression. Nevertheless, most Bcl-2 family members are expressed at a basal level, both in tissues and in cultured cells. The presence of Bcl-2 family members, both in proliferating and post-mitotic cells, might not only reflect the requirement for a rapid response to apoptotic stimuli, but also non-apoptotic functions of these proteins. Namely, it 
has been shown that both Bcl-2 and Bcl-xL could regulate autophagy (Pattingre et al., 2005; Maiuri et al., 2007; Priault et al., 2010; Beaumatin et al., 2016). Interestingly, the effects of both proteins on autophagy are distinct, paralleling their distinct effect on Bax-regulation discussed above. It has also been shown that Bax could regulate mitochondrial dynamics (Karbowski et al., 2006; Cleland et al., 2011). In this short survey, we have shown that, even in non-apoptotic cells, the interactions between pro- and anti-apoptotic Bcl-2 family members determine the way a cell is able to respond to a potential apoptotic trigger, such as an anti-tumoral treatment. The fact that these properties are conserved in yeast demonstrates that they are dependent on their intrinsic molecular features. As a matter of fact, the heterologous expression in yeast continues to be an outstanding tool to study the molecular mechanisms underlying the function of these proteins.

\section{Aknowledgements}

The work in the lab of the authors has been supported by the CNRS, the ANR, the University of Bordeaux (to S.M.) and the California State University of Fresno (to L.M.D.).

\section{References}

Adams, J.M., Cory, S., 2007. The Bcl-2 apoptotic switch in cancer development and therapy. Oncogene 26, 1324-1337.

Antonsson, B., Montessuit, S., Lauper, S., Eskes, R., Martinou, J.C., 2000. Bax oligomerization is required for channel-forming activity in liposomes and to trigger cytochrome c release from mitochondria. Biochem. J. 345, 271-278.

Antonsson, B., Montessuit, S., Sanchez, B., Martinou, J.C., 2001. Bax is present as a high molecular weight oligomer/complex in the mitochondrial membrane of apoptotic cells. J. Biol. Chem. 276, 11615-11623

Aouacheria, A., Rech de Laval, V., Combet, C., Hardwick, J.M., 2013. Evolution of Bcl-2 homology motifs: homology versus homoplasy. Trends Cell Biol. 23, 103-111.

Aouacheria, A., Combet, C., Tompa, P., Hardwick, J.M., 2015. Redefining the BH3 Death Domain as a 'Short Linear Motif'. Trends Biochem Sci. 40, 736-748.

Arokium, H., Camougrand, N., Vallette, F.M., Manon, S., 2004. Studies of the interaction of substituted mutants of BAX with yeast mitochondria reveal that the $\mathrm{C}$-terminal hydrophobic alpha- 
helix is a second ART sequence and plays a role in the interaction with anti-apoptotic BCL-xL. J. Biol. Chem. 279, 52566-52573.

Arokium, H., Ouerfelli, H., Velours, G., Camougrand, N., Vallette, F.M., Manon, S. 2007., Substitutions of potentially phosphorylatable serine residues of Bax reveal how they may regulate its interaction with mitochondria. J. Biol. Chem. 282, 35104-35112.

Baines, C.P., Kaiser, R.A., Purcell, N.H., Blair, N.S., Osinska, H., Hambleton, M.A., Brunskill, E.W., Sayen, M.R., Gottlieb, R.A., Dorn, G.W., Robbins, J., Molkentin, J.D., 2005. Loss of cyclophilin D reveals a critical role for mitochondrial permeability transition in cell death. Nature 434, 658-662.

Bellot, G., Cartron, P.F., Er, E., Oliver, L., Juin, P., Armstrong, L.C., Bornstein, P., Mihara, K., Manon, S., Vallette, F.M., 2007. TOM22, a core component of the mitochondria outer membrane protein translocation pore, is a mitochondrial receptor for the proapoptotic protein Bax. Cell Death Differ. 14, 785-794

Beaumatin, F., El Dhaybi, M., Lasserre, J.P., Salin, B., Moyer, M.P., Verdier, M., Manon, S., Priault, M., 2016. N52 monodeamidated Bcl-xL shows impaired oncogenic properties in vivo and in vitro. Oncotarget 7, 17129-17143

Bernardi, P., Rasola, A., Forte, M., Lippe, G., 2015. The Mitochondrial Permeability Transition Pore: Channel Formation by F-ATP Synthase, Integration in Signal Transduction, and Role in Pathophysiology. Physiol Rev. 95, 1111-1155.

Bleicken, S., Jeschke, G., Stegmueller, C., Salvador-Gallego, R., García-Sáez, A.J., Bordignon, E., 2014. Structural model of active Bax at the membrane. Mol. Cell. 56, 496-505.

Büttner, S., Ruli, D., Vögtle, F.N., Galluzzi, L., Moitzi, B., Eisenberg, T., Kepp, O., Habernig, L., Carmona-Gutierrez, D., Rockenfeller, P., Laun, P., Breitenbach, M., Khoury, C., Fröhlich, K.U., Rechberger, G., Meisinger, C., Kroemer, G., Madeo, F., 2011. A yeast BH3-only protein mediates the mitochondrial pathway of apoptosis. EMBO J. 30, 2779-2792.

Cartron, P.F., Arokium, H., Oliver, L., Meflah, K., Manon, S., Vallette, F.M., 2005. Distinct domains control the addressing and the insertion of Bax into mitochondria. J. Biol. Chem. 280, 10587-10598 
Castilla, C., Congregado, B., Chinchón, D., Torrubia, F.J., Japón, M.A., Sáez, C., 2006. Bcl-xL is overexpressed in hormone-resistant prostate cancer and promotes survival of LNCaP cells via interaction with proapoptotic Bak. Endocrinology 147, 4960-4967

Cebulski, J., Malouin, J., Pinches, N., Cascio, V., Austriaco, N., 2011. Yeast Bax inhibitor, Bxi1p, is an ER-localized protein that links the unfolded protein response and programmed cell death in Saccharomyces cerevisiae. PLoS One 6, e20882.

Certo, M., Del Gaizo Moore, V., Nishino, M., Wei, G., Korsmeyer, S., Armstrong, S.A., Letai, A., 2006. Mitochondria primed by death signals determine cellular addiction to antiapoptotic BCL-2 family members. Cancer Cell 9, 351-365.

Chang, Y., Bruni, R., Kloss, B., Assur, Z., Kloppmann, E., Rost, B., Hendrickson, W.A., Liu, Q., 2014. Structural basis for a pH-sensitive calcium leak across membranes. Science 344, 1131-1135.

Cheng, W.C., Leach, K.M., Hardwick, J.M., 2008. Mitochondrial death pathways in yeast and mammalian cells. Biochim Biophys Acta 1783, 1272-1279

Chou, J.J., Li, H., Salvesen, G.S., Yuan, J., Wagner, G., 1999. Solution structure of BID, an intracellular amplifier of apoptotic signaling. Cell 96, 615-624.

Cleland, M.M., Norris, K.L., Karbowski, M., Wang, C., Suen, D.F., Jiao, S., George, N.M., Luo, X., Li, Z., Youle, R.J., 2011. Bcl-2 family interaction with the mitochondrial morphogenesis machinery. Cell Death Differ. 18, 235-247.

Colombini, M., 2010. Ceramide channels and their role in mitochondria-mediated apoptosis. Biochim Biophys Acta 1797, 1239-1244

Czabotar, P.E., Lessene, G., Strasser, A., Adams, J.M., 2014. Control of apoptosis by the BCL-2 protein family: implications for physiology and therapy. Nat. Rev. Mol. Cell Biol. 15, 49-63.

Eisenberg, T., Büttner, S., Kroemer, G., Madeo, F., 2007. The mitochondrial pathway in yeast apoptosis. Apoptosis 12, 1011-1023. 
Edlich, F., Banerjee, S., Suzuki, M., Cleland, M.M., Arnoult, D., Wang, C., Neutzner, A., Tjandra,

N., Youle, R.J., 2011. Bcl-x(L) retrotranslocates Bax from the mitochondria into the cytosol. Cell $145,104-116$.

Gallenne, T., Gautier, F., Oliver, L., Hervouet, E., Noël, B., Hickman, J.A., Geneste, O., Cartron, P.F., Vallette, F.M., Manon, S., Juin, P., 2009. Bax activation by the BH3-only protein Puma promotes cell dependence on antiapoptotic Bcl-2 family members. J. Cell Biol. 185, 279-290.

Gardai, S.J., Hildeman, D.A., Frankel, S.K., Whitlock, B.B., Frasch, S.C., Borregaard, N., Marrack, P., Bratton, D.L., Henson, P.M., 2004. Phosphorylation of Bax Ser184 by Akt regulates its activity and apoptosis in neutrophils. J. Biol. Chem. 279, 21085-21095.

Gautier, F., Guillemin, Y., Cartron, P.F., Gallenne, T., Cauquil, N., Le Diguarher, T., Casara, P., Vallette, F.M., Manon, S., Hickman, J.A., Geneste, O., Juin, P., 2011. Bax activation by engagement with, then release from, the BH3 binding site of Bcl-xL. Mol. Cell. Biol. 31, 832-844.

Gérecová, G., Kopanicová, J., Jaká, P., Běhalová, L., Juhásová, B., Bhatia-Kiššová, I., Forte, M., Polčic, P., Mentel, M., 2013. BH3-only proteins Noxa, Bik, Bmf, and Bid activate Bax and Bak indirectly when studied in yeast model. FEMS Yeast Res. 13, 747-754.

Gonzalez, D.H., Neupert, W., 1990. Biogenesis of mitochondrial c-type cytochromes. J. Bioenerg. Biomembr. 22, 753-768

Gonzalvez, F., Bessoule, J.J., Rocchiccioli, F., Manon, S., Petit, P.X., 2005. Role of cardiolipin on tBid and tBid/Bax synergistic effects on yeast mitochondria. Cell Death Differ. 12, 659-667.

Große, L., Wurm, C.A., Brüser, C., Neumann, D., Jans, D.C., Jakobs, S., 2016. Bax assembles into large ring-like structures remodeling the mitochondrial outer membrane in apoptosis. EMBO J. 35, 402-413

Hsu, Y.T., Youle, R.J., 1997. Nonionic detergents induce dimerization among members of the Bcl-2 family. J. Biol. Chem. 272, 13829-13834.

Jürgensmeier, J.M., Xie, Z., Deveraux, Q., Ellerby, L., Bredesen, D., Reed, J.C., 1998. Bax directly induces release of cytochrome c from isolated mitochondria. Proc. Natl Acad. Sci U S A. 95, 4997- 
5002.

Karbowski, M., Norris, K.L., Cleland, M.M., Jeong, S.Y., Youle, R.J., 2006. Role of Bax and Bak in mitochondrial morphogenesis. Nature 443, 658-662.

Kissová, I., Plamondon, L.T., Brisson, L., Priault, M., Renouf, V., Schaeffer, J., Camougrand, N., Manon, S., 2006. Evaluation of the roles of apoptosis, autophagy, and mitophagy in the loss of plating efficiency induced by Bax expression in yeast. J. Biol. Chem. 281, 36187-36197.

Kroemer, G., Galluzzi, L., Brenner, C., 2007. Mitochondrial membrane permeabilization in cell death. Physiol Rev. 87, 99-163.

Laloux, G., Deghelt, M., de Barsy, M., Letesson, J.J., De Bolle, X. 2010. Identification of the essential Brucella melitensis porin Omp2b as a suppressor of Bax-induced cell death in yeast in a genome-wide screening. PLoS One 5, e13274.

Liang, X.H., Jackson, S., Seaman, M., Brown, K., Kempkes, B., Hibshoosh, H., Levine, B., 1999. Induction of autophagy and inhibition of tumorigenesis by beclin 1. Nature 402, 672-676.

Lindqvist, L.M., Heinlein, M., Huang, D.C., Vaux, D.L., 2014. Prosurvival Bcl-2 family members affect autophagy only indirectly, by inhibiting Bax and Bak. Proc. Natl Acad. Sci. USA. 111, 85128517.

Linseman, D.A., Butts, B.D., Precht, T.A., Phelps, R.A., Le, S.S., Laessig, T.A., Bouchard, R.J., Florez-McClure, M.L., Heidenreich, K.A., 2004. Glycogen synthase kinase-3beta phosphorylates Bax and promotes its mitochondrial localization during neuronal apoptosis. J. Neurosci. 24, 999310002.

Maiuri, M.C., Le Toumelin, G., Criollo, A., Rain, J.C., Gautier, F., Juin, P., Tasdemir, E., Pierron, G., Troulinaki, K., Tavernarakis, N., Hickman, J.A., Geneste, O., Kroemer, G., 2007. Functional and physical interaction between Bcl-X(L) and a BH3-like domain in Beclin-1. EMBO J. 26, 25272539.

Manon, S., Chaudhuri, B., Guérin, M., 1997. Release of cytochrome c and decrease of cytochrome c oxidase in Bax-expressing yeast cells, and prevention of these effects by coexpression of Bcl-xL. 
FEBS Lett. 415, 29-32.

Margoliash, E., Fitch, W.M., 1968. Evolutionary variability of cytochrome c primary structures. Ann. N.Y. Acad. Sci. 151, 359-381

Martinez-Caballero, S., Dejean, L.M., Kinnally, M.S., Oh, K.J., Mannella, C.A., Kinnally, K.W., Assembly of the mitochondrial apoptosis-induced channel, MAC. J. Biol. Chem. 284, 1223512245.

Martini, M., De Santis, M.C., Braccini, L., Gulluni, F., Hirsch, E., 2014. PI3K/AKT signaling pathway and cancer: an updated review. Ann. Med. 46, 372-383

Ottilie, S., Diaz, J.L.,Chang, J., Wilson G., Tuffo, K.M., Weeks, S., McConnell, M., Wang, Y., Oltersdorf, T., Fritz, L.C., 1997. Structural and functional complementation of an inactive Bcl-2 mutant by Bax truncation. J. Biol. Chem. 272, 16955-16961

Owens, T.W., Valentijn, A.J., Upton, J.P., Keeble, J., Zhang, L., Lindsay, J., Zouq, N.K., Gilmore, A.P., 2009. Apoptosis commitment and activation of mitochondrial Bax during anoikis is regulated by p38MAPK. Cell Death Differ. 16, 1551-1562.

Pan, L., Kawai, M., Yu, L.H., Kim, K.M., Hirata, A., Umeda, M., Uchimiya, H., 2001. The Arabidopsis thaliana ethylene-responsive element binding protein (AtEBP) can function as a dominant suppressor of Bax-induced cell death of yeast. FEBS Lett. 508, 375-378.

Pattingre, S., Tassa, A., Qu, X., Garuti, R., Liang, X.H., Mizushima, N., Packer, M., Schneider, M.D., Levine, B., 2005. Bcl-2 antiapoptotic proteins inhibit Beclin 1-dependent autophagy. Cell $122 ; 927-939$.

Pena, J.C., Thompson, C.B., Recant, W., Vokes, E.E., Rudin, C.M., 1999. Bcl-xL and Bcl-2 expression in squamous cell carcinoma of the head and neck. Cancer 85, 164-170.

Pereira, C., Silva, R.D., Saraiva, L., Johansson, B., Sousa, M.J., Côrte-Real, M., 2008. Mitochondria-dependent apoptosis in yeast. Biochim Biophys Acta 1783, 1286-1302.

Pereira, C., Chaves, S., Alves, S., Salin, B., Camougrand, N., Manon, S., Sousa, M.J., Côrte-Real, 
M., 2010. Mitochondrial degradation in acetic acid-induced yeast apoptosis: the role of Pep4 and the ADP/ATP carrier. Mol Microbiol. 76, 1398-1410.

Peyerl, F.W., Dai, S., Murphy, G.A., Crawford, F., White, J., Marrack, P., Kappler, J.W., 2007. Elucidation of some Bax conformational changes through crystallization of an antibody-peptide complex. Cell Death Differ. 14, 447-452

Renault, T.T., Manon, S., 2011. Bax: Addressed to kill. Biochimie 93, 1379-1391.

Renault, T.T., Grandier-Vazeille, X., Arokium, H., Velours, G., Camougrand, N., Priault, M., Teijido, O., Dejean, L.M., Manon, S, 2012. The cytosolic domain of human Tom22 modulates human Bax mitochondrial translocation and conformation in yeast. FEBS Lett. 586, 116-121

Renault, T.T., Teijido, O., Antonsson, B., Dejean, L.M., Manon, S., 2013. Regulation of Bax mitochondrial localization by $\mathrm{Bcl}-2$ and $\mathrm{Bcl}-\mathrm{x}(\mathrm{L})$ : keep your friends close but your enemies closer. Int. J. Biochem. Cell. Biol. 45, 64-67

Renault, T.T., Teijido, O., Missire, F., Ganesan, Y.T., Velours, G., Arokium, H., Beaumatin, F., Llanos, R., Athané, A., Camougrand, N., Priault, M., Antonsson, B., Dejean, L.M., Manon, S., 2015. Bcl-xL stimulates Bax relocation to mitochondria and primes cells to ABT-737. Int. J. Biochem. Cell. Biol. 64, 136-146.

Salvador-Gallego, R., Mund, M., Cosentino, K., Schneider, J., Unsay, J., Schraermeyer, U., Engelhardt, J., Ries, J., García-Sáez, A.J. 2016. Bax assembly into rings and arcs in apoptotic mitochondria is linked to membrane pores. EMBO J. 35, 389-401.

Schellenberg, B., Wang, P., Keeble, J.A., Rodriguez-Enriquez, R., Walker, S., Owens, T.W., Foster, F., Tanianis-Hughes, J., Brennan, K., Streuli, C.H., Gilmore, A.P., 2013. Bax exists in a dynamic equilibrium between the cytosol and mitochondria to control apoptotic priming. Mol. Cell 49, 959971.

Simonyan, L., Renault, T.T., da Costa Novais, M.J., Sousa, M.J., Côrte-Real, M., Camougrand, N., Gonzalez, C., Manon, S., 2016. Regulation of Bax/mitochondria interaction by AKT. FEBS Lett. 590, 13-21. 
Subburaj, Y., Cosentino, K., Axmann, M., Pedrueza-Villalmanzo, E., Hermann, E., Bleicken, S., Spatz, J., García-Sáez, A.J. 2015. Bax monomers form dimer units in the membrane that further self-assemble into multiple oligomeric species. Nat. Commun. 6, 8042.

Suzuki, M., Youle, R.J., Tjandra, N., 2000. Structure of Bax: coregulation of dimer formation and intracellular localization. Cell 103, 645-654.

Tang, L., Tron, V.A., Reed, J.C., Mah, K.J., Krajewska, M., Li, G., Zhou, X., Ho, V.C., Trotter, M.J., 1998. Expression of apoptosis regulators in cutaneous malignant melanoma. Clin Cancer Res. 4, 1865-1871.

Teijido, O., Dejean, L. 2010. Upregulation of Bcl2 inhibits apoptosis-driven BAX insertion but favors BAX relocalization in mitochondria. FEBS Lett. 584, 3305-3310.

Todt, F., Cakir, Z., Reichenbach, F., Youle, R.J., Edlich, F., 2013. The C-terminal helix of Bcl-x(L) mediates Bax retrotranslocation from the mitochondria. Cell Death Differ. 20, 333-342.

Tsujimoto, Y., Nakagawa, T., Shimizu, S., 2006. Mitochondrial membrane permeability transition and cell death. Biochim. Biophys. Acta. 1757, 1297-1300.

Ubaidillah, M., Kim, K.A., Kim, Y.H., Lee, I.J., Yun, B.W., Kim, D.H., Loake, G.J., Kim, K.M., 2013. Identification of a drought-induced rice gene, OsSAP, that suppresses Bax-induced cell death in yeast. Mol. Biol. Rep. 40, 6113-6121

Westphal, D., Dewson, G., Menard, M., Frederick, P., Iyer, S., Bartolo, R., Gibson, L., Czabotar, P.E., Smith, B.J., Adams, J.M., Kluck, R.M., 2014. Apoptotic pore formation is associated with inplane insertion of Bak or Bax central helices into the mitochondrial outer membrane. Proc. Natl Acad. Sci. U S A. 111, E4076-E4085.

Wolter, K.G., Hsu, Y.T., Smith, C.L., Nechushtan, A., Xi, X.G., Youle, R.J., 1997. Movement of Bax from the cytosol to mitochondria during apoptosis. J. Cell Biol. 139, 1281-1292.

Xin, M., Gao, F., May, W.S., Flagg, T., Deng, X., 2007. Protein kinase Czeta abrogates the proapoptotic function of Bax through phosphorylation. J. Biol. Chem. 282, 21268-21277. 
Xu, Q., Reed, J.C., 1998. Bax inhibitor-1, a mammalian apoptosis suppressor identified by functional screening in yeast. Mol. Cell 1, 337-346. 


\section{Legends to Figures}

Figure 1. Schematic representation of the classification of Bcl-2 family members and BH3containing proteins.

TOP: Classical representation of the Bcl-2 family members, bases on their function (anti- $v / s$ proapoptotic) and on their structure (multidomain v/s BH3-only).

BOTTOM: Phylogenetic classification based on the evolution of $\mathrm{BH}$ domains . True Bcl-2 homologs include multidomain proteins (anti- and pro-apoptotic) and Bid, that has a structure closely related to that of Bcl-xL (Chou et al., 1999). BH3-domains can be divided into canonical domains, that are evolutionary related to those of Bcl-2 homologs, and non-canonical domains, that might proceed from a convergent evolution (Aouacheria et al., 2013, 2015).

\section{Figure 2. Mitochondrial proteins released during cell death in mammals and yeast.}

TOP: In mammalian cells, Bax/Bak-dependent apoptosis is associated to the formation of a large pore in the MOM, that allows the release of cytochrome c. It remains however unclear if this pore also allows the release of other factors. Necrosis and late apoptosis are associated to the opening of $\mathrm{mPTP}$, that induces a non-selective release of all the factors localized in the intermembrane space. BOTTOM: In yeast, the heterologous expression of Bax is associated to the formation or the same pore as in mammals, supporting that this pore contains Bax (Pavlov et al., 2001). Other factors can be released following death signals specific to yeast, such as acetic acid treatments (Pereira et al., 2010). However, Bax effects in yeast do not depend on these factors (Kissova et al., 2006).

Figure 3. Measurement of Bax-driven release of cytochrome c from yeast mitochondria by redox spectrophotometry and immunoblotting.

Mitochondria were isolated from yeast cells expressing wild-type Bax (BaxWT, poorly active) or a constitutively mitochondrial and active mutant Bax-P168A (Arokium et al., 2004).

LEFT: Redox spectrophotometry measurements. A mitochondrial suspension (3-5mg protein/mL) was placed in the cuvettes of a double-beam spectrophotometer. The reference cuvette was oxidized with potassium ferricyanide and the sample cuvette was reduced with sodium dithionite. The difference spectra were acquired between 500 and 650nm. Cytochrome $\mathrm{c}+\mathrm{c} 1$ and cytochrome $\mathrm{b}$ contents were calculated from the height of the peaks, as indicated, and manually corrected with the difference of the isobestic points at $540 \mathrm{~nm}$ and $575 \mathrm{~nm}$. A molar extinction coefficient of $18,000 \mathrm{M}^{-}$ ${ }^{1} . \mathrm{cm}^{-1}$ for both types of cytochromes was used, and cytochrome $\mathrm{c}$ was calculated by considering that the stoechiometry cytochrome b/cytochrome $\mathrm{c} 1$ is 2 .

RIGHT: Immunoblotting measurements. $100 \mu \mathrm{g}$ of mitochondrial proteins or of post-mitochondrial 
supernatants were blotted, and immunodetected with a custom antibody against yeast cytochrome c. Antibodies against Phosphoglycerate Kinase (Pgk) and subunit 2 of respiratory complex IV (Cox2) were used as loading controls. The immunoblotting against Bax shows that the mutant Bax-P168A is more localized in mitochondria than BaxWT (Renault et al., 2015).

\section{Figure 4. Comparison of the effects of full-length Bcl-xL and truncated Bcl-xL $\Delta C$ on Bax mitochondrial localization.}

LEFT: Bax is under a dynamic equilibrium between mitochondria and cytosol, owing to the processes of $\mathrm{Bcl}-\mathrm{xL}$-driven translocation and retrotranslocation. Mitochondrial Bax is primed but remains inactive because of the interaction with $\mathrm{Bcl}-\mathrm{xL}$. The addition of a $\mathrm{BH} 3$-mimetic (or the expression of a $\mathrm{BH} 3$-only partner) enables the derepression of the interaction and the full activation of Bax.

RIGHT: Bcl-xL $\Delta \mathrm{C}$ stimulates the ttanslocation but not the retrotranslocation, leading to a higher mitochondrial Bax content. Furthermore, the interaction between Bax and Bcl-xL $\Delta \mathrm{C}$ is weak, and Bax can be fully activated without the need of a BH3-mimetic. 